\title{
$\begin{array}{ll}\text { Research Square } & \text { Preprints are preliminary reports that have not undergone peer review. } \\ \text { They should not be considered conclusive, used to inform clinical practice, }\end{array}$ or referenced by the media as validated information. \\ Effect of Texture on Energy Consumption for High Frequency Hydraulic Impact Piston Pair
}

\section{Hu Mo}

Hunan University of Science and Technology

Yong Guo ( $\sim$ hnkjdx_guoy@163.com )

Hunan University of Science and Technology

Hu Yanping

Hunan University of Science and Technology

\section{Song Quan}

Hunan University of Science and Technology

\section{Zhewu Chen}

Hunan University of Science and Technology

\section{Original Article}

Keywords: hydraulic impactor, impact piston pair, energy consumption, surface texture, cylindrical microtexture

Posted Date: November 17th, 2020

DOl: https://doi.org/10.21203/rs.3.rs-106437/v1

License: (c) (i) This work is licensed under a Creative Commons Attribution 4.0 International License. Read Full License 


\section{Title page}

\section{Effect of Texture on Energy Consumption for High Frequency Hydraulic Impact Piston Pair}

Hu Mo, born in 1985, is currently a PhD candidate at Hunan Provincial Key Laboratory of Health Maintenance for Mechanical Equipment, Hunan University of Science and Technology, China.

E-mail: 18229849289@163.com

Yong Guo, born in 1985, is currently a professor at Hunan University of Science and Technology, China. He received his master degree in Zhongnan University, China.

E-mail: hnkjdx_guoy@163.com

Yanping Hu, born in 1957, is currently a professor at Hunan University of Science and Technology, China. He received his master degree in Zhongnan University, China.

E-mail: yphu@hunst.edu.cn

Song Quan, born in 1997, is currently a master candidate at Hunan Provincial Key Laboratory of Health Maintenance for Mechanical Equipment, Hunan University of Science and Technology, China.

E-mail: hnust_qs0425@163.com.

Zhewu Chen, born in 1984, is currently an professor at Hunan University of Science and Technology, China. He received his $\mathrm{PhD}$ degree from Hunan Universtiy, China.

E-mail: 258269681@qq.com

Corresponding author: Yong Guo E-mail: hnkjdx_guoy@163.com 


\title{
ORIGINAL ARTICLE
}

\section{Effect of Texture on Energy Consumption for High Frequency Hydraulic Impact Piston Pair}

\author{
Hu Mo ${ }^{1,2} \cdot$ Yong Guo $^{1} \cdot$ Yanping Hu$^{1} \cdot \operatorname{Song}$ Quan $^{1} \cdot$ Zhewu Chen $^{1}$
}

\begin{abstract}
Limited by the influence of the traditional clearance seal structure on the leakage and friction loss of the piston pair, the energy utilization ratio of the hydraulic impactor is difficult to improve. As such, a novel clearance seal structure with cylindrical texture for the impact piston is proposed to solve it. Considering the leakage and friction loss of impact piston pair, an energy consumption evaluation index is put forward. Based on the average Reynolds equation, an energy consumption analysis model for a textured high-frequency hydraulic impact piston pair is established, and the influence of piston texture parameters for the YG45 hydraulic impactor on energy consumption under rated working conditions is studied. The results show that energy consumption of an impact piston pair accounts for $29.77 \%$ of total energy loss. The variation of area ratio textured makes the ratio of energy consumption to the piston pair decline $1.32 \%$ 10.98\%, where the optimum area rate textured is $0.64 \sim 0.7$. The variation of depth ratio textured leads to the reduction of the ratio of energy consumption to piston pair by $3.21 \% \sim 5.68 \%$, where the optimum depth ratio textured is $1 \sim 1.1$.The texture structure of the piston pair significantly reduces the energy consumption of the impact piston pair, and it is an effective approach to avoid the design dilemma for the conventional impact piston pair.
\end{abstract}

Key Words: hydraulic impactor; impact piston pair; energy consumption; surface texture; cylindrical micro-texture

\section{Introduction}

The energy utilization ratio of the hydraulic impactor ${ }^{1}$ is the ratio of piston impact energy to hydraulic energy. It reflects the conversion efficiency from hydraulic energy to

\footnotetext{
$1 \bowtie$ Yong Guo

hnkjdx_guoy@163.com

${ }^{1}$ Hunan Provincial Key Laboratory of Health Maintenance for Mechanical Equipment, Hunan University of Science and Technology, HuNan Xiangtan 411201, China;

${ }^{2}$ Hunan Electrical College of Technology, Xiangtan 411201, China;
}

mechanical energy of the hydraulic impactor, and directly affects the drilling efficiency of the hydraulic impactor [1-2]. In the process of high frequency reciprocating, the friction loss and leakage loss of the piston pair are import parts in total energy loss during energy transformation of the hydraulic impactor. The friction loss of the piston pair is caused by clearance lubricationbetween the impact piston and cylinder block, as well as the leakage loss caused by clearance seal. In order to improve the energy utilization rate of hydraulic impactor, scholars at home and abroad have conducted a significant amount of research on the energy consumption calculation of impact piston pairs and the optimization of piston structural parameters. Through an analysis of a rock drill impact module, Oh developed the impact performance analysis tool and analyzed the variation law of energy utilization rate for hydraulic impactor relative to rock stiffness [3]. Taking into considering the leakage and friction of impact piston pair, Seo analyzed the performance of the hydraulic impactor through simulation, then put forward the design method of structural parameters of the impact piston and determined the range of piston parameters [4]. Flegner tested the friction and wear of piston during the drilling process of hydraulic impactor under different drilling pressures and rotational speeds. In view of avoiding premature wear, the design method of piston structure parameters for enhancing the lubrication effect was put forward and the range of piston parameters was determined [5]. Wang also established a kinematics mathematical model of the impact piston for the hydraulic impactor based on Reynolds equation. The bearing capacity, cavity pressure, friction force and friction energy consumption of the piston pair were studied [6]. However, it is still limited to the conventional clearance lubrication and sealing mechanism in the design optimization of the impact piston pairs mentioned above, making it difficult to realize the design of declining energy consumption for the impact piston hard to realize. Increasing clearance reduces friction loss with the increase of leakage loss, and decreasing clearance decreases leakage loss with the increase of friction loss. This brings about the failure of energy utilization improvement for the hydraulic impactor, causing energy utilization rate of the hydraulic impactor to 
be much lower than that of other hydraulic actuators.

Surface texture is a micro geometric structure fabricated by special manufacturing technology on the surface with certain size, shape, and arrangement, such as micro pits and grooves. The additional hydrodynamic lubrication effect of texture can be used to improve the surface bearing capacity and reduce the surface friction [7-8]. It has been widely recognized as an effective method in reducing friction, declining wear and increasing surface bearing capacity [9-11]. Pit texture was applied to the surface of the cylinder liner of an internal combustion engine to improve the lubricity of the piston pair, and the friction between the piston ring and cylinder liner was greatly reduced accordingly [12]. The groove texture was applied to the bearing surface to reduce the friction on the bearing surface with a better stability working parameter [13]. It has also been demonstrated by a number of scholars that different morphologies and parameters of texture have a significant influence on surface friction loss. Zhang studied the friction force of surface texture parallel sliders with different morphologies, and found that the hydrodynamic lubrication performance of circular textures is better with a lower friction coefficient [14]. Gropper analyzed the performance of bearing with variation of texture area and textured depth on surface determining that the optimum texture depth should be slightly less than the minimum film thickness of unreformed bearing, and that there existed an optimum texture depth and density with low friction existed [15]. Wang conducted research on texture density, and discovered that the friction force reduced favorably with a texture density of $5 \% \sim 13 \%$.

In order to improve energy efficiency of the hydraulic impactor, the impact piston pair structure with cylindrical texture is proposed. By analyzing the physical and mechanical mechanisms of energy consumption of the impact piston pair, energy consumption analysis model of the impact piston pair is established, then solved numerically combined with the Reynolds equation. The effect of texture parameters on the energy consumption of the impact piston is obtained, which provides a theoretical basis to design a high frequency hydraulic impactor with surface texture on the impact piston.

\section{Physical model of the textured impact piston pair with high frequency}

\subsection{Geometric model of the impact piston pair with high frequency}

The impact piston pair with high frequency is widely used in various kinds of impact machinery. The piston pair used in the impact mechanism of the YG45 hydraulic rock drill falls into this category, which is shown in Fig. 1. It presents characteristics of periodic motion with high frequency and varied velocity. The impact mechanism of the drill is composed of the impact piston, cylinder block, cylinder sleeve, front support seat, rear support seat, front chamber, and rear chamber. The front chamber is usually filled with high-pressure oil, and the rear chamber is alternately filled with both the high-pressure oil and the return oil. The impact piston moves under the pressure of the front and rear chamber.

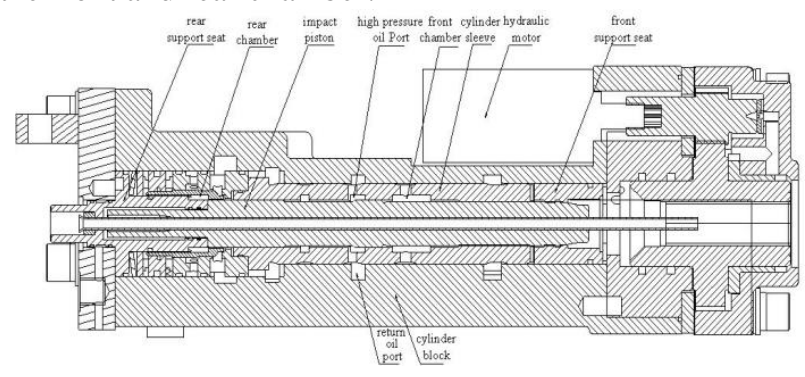

Fig. 1 Impact mechanism of the YG45 hydraulic rock drill In the impact piston pair, clearance seal is used between the impact piston and cylinder sleeve, and the clearance value is generally set to $55-65 \mu \mathrm{m}$. The piston support seat is arranged in the front and rear of the cylinder block to support and guide the impact piston. In the working process of hydraulic impactor, high-pressure oil flows from the inlet into the cylinder block, as well as the front and rear chamber. Due to the difference of the bearing area of the front and rear chamber, the impact piston moves towards the right with great acceleration under the action of the pressure difference. When the load changes on both ends of the sleeve valve, the oil path will be switched. The front chamber is filled with high-pressure oil, and the rear chamber is filled with return oil. High-pressure oil within the front chamber pushes the impact piston to move leftward with acceleration.

\subsection{Surface texture model of the impact piston}

Taking the impact piston pair in a high frequency hydraulic impactor as the research object, the impact piston and cylinder block are fitted with clearance, the cylindrical micro-texture is machined onto the shoulder surface of the piston seal table, and the seal length is 40 $\mathrm{mm}$. The shoulder surface is completely textured along the axial direction. According to the confinement of the unit area of microtexture, a total of 1647 microtexture units can be machined. The distribution of circular microtexture is presented in Fig. 2. 


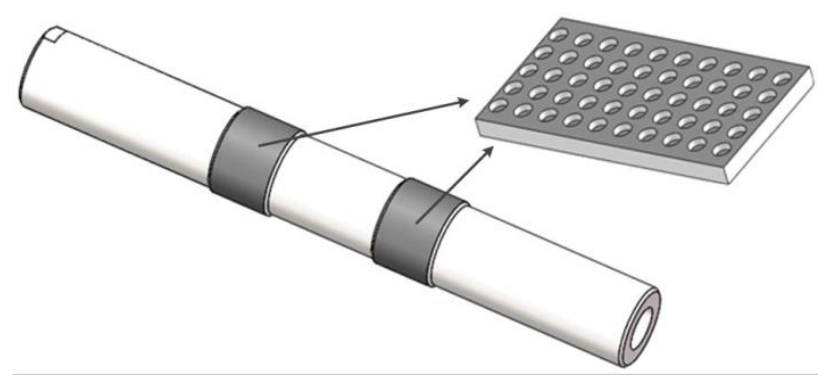

Fig. 2 Cylindrical texture geometric model of the impact piston surface

The impact piston diameter in the diagram is $30 \mathrm{~mm}$, and total length of the seal is $40 \mathrm{~mm}$. The radial dimension of the oil film thickness and texture is significantly smaller than the diameter of the piston. The influence of the curvature radius of oil film can be ignored, and the surface of the piston can be equivalently expanded into a plane equivalently[16]. The distribution of oil film thickness and oil film pressure varies regularly in each micro-texture unit region, and the pit texture is periodically distributed periodically. The oil film thickness and oil film pressure also change periodically in each texture unit region, so a single microtexture control unit is studied. The pressure and friction of the entire sealing area are then approximately according to the characteristics of its periodic arrangement [17]. The geometric model of the microtexture control unit is presented in Fig.3.

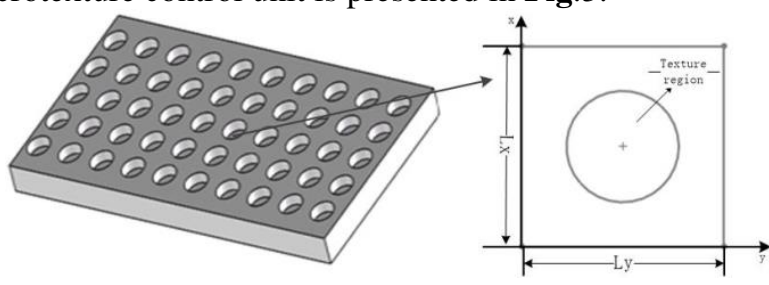

Fig. 3 Geometric model of the texture control unit

The coordinate system is established on the piston surface, in which the $x$-axis is along the axis of the piston, and the $y$-axis is set in radial direction of the piston. $L_{x}$ is the length of the control unit along the $x$-axis, and $L_{y}$ is the length of the control unit along the $y$-axis. $A$ is the area of control unit. The area rate textured is $S_{p}$, and it can be expressed as:

$$
S_{p}=\frac{A}{L_{x} L_{y}}
$$

\section{Analysis model of energy consumption for the textured impact piston pair with high frequency}

A hypothesis is put forward to establish an analysis model of energy consumption for the textured impact piston pair with high frequency. The clearance of the piston and the cylinder block is assumed to fill with oil, whereas the hydraulic oil is assumed not to slip on the piston surface. In other words, the velocity of the oil attached to the surface of the piston is the same as the velocity of the piston. The curvature radius of the piston surface is rather large compared with the thickness of the clearance oil film, and so the influence of the oil film curvature is ignored. Hydraulic oil is assumed to have the characteristics of Newtonian fluid. The viscosity value of hydraulic oil is regarded as a constant value along the thickness of the clearance oil film. The cylinder block is considered as a rigid body, whereas the impact piston is considered as an elastic body. The impact piston pair of hydraulic impactor works vertically and is used with a guiding device, so the influence of gravity and radial force to the eccentricity of the impact piston is very small. Additionally, both the piston and inner hole of the cylinder body are manufactured with high machining roundness. With these conditions, the eccentricity of the working impact piston is ignored. The change of hydraulic oil temperature during piston movement is also disregarded.

\subsection{Energy consumption evaluation index of the impact piston pair}

In the process of high frequency reciprocating, the friction loss and leakage loss of the piston pair are important parts of the total energy loss during the energy transformation of hydraulic impactor. The friction loss of the piston pair is caused by clearance lubrication between the impact piston and cylinder block, and the clearance seal causes leakage loss. In this paper, the energy consumption for the impact piston pair is evaluated in a cycle that takes into consideration both the friction loss and leakage loss. During the movement of the impact piston, the clearance between the impact piston and cylinder block is filled with hydraulic oil to avoid direct contact with the cylinder block. The relative motion of the impact piston and cylinder block results in dynamic oil film in the clearance. The shearing force of oil causes the friction force of dynamic pressure oil film on a solid surface. When the velocity of the impact piston increases, the friction forces increase due to the increase in shear force. In addition, the seal form between the impact piston and cylinder block is the clearance seal. Hydraulic oil leakage exists at the two ends of the impact piston pair under the action of the pressure difference between two ends of the impact piston, causing leakage loss. Considering the leakage and friction loss of the impact piston pair, the energy consumption of the impact piston pair in one cycle is calculated as follows:

$$
W=W_{L}+W_{F}=\int_{0}^{T} P_{L t} d t+\int_{0}^{T} P_{F t} d t
$$

where $W$ is the energy consumption of the impact piston pair in one cycle, $W_{L}$ is the leakage loss of the impact piston pair in one cycle, $W_{F}$ is the friction loss of the 
impact piston pair in one cycle, $P_{L t}$ is the leakage power of the impact piston pair at time $t, P_{F t}$ is the friction power of impact piston pair at time $t, T$ is the motion cycle of the hydraulic impactor with high frequency.

\subsection{Leakage loss calculation}

Leakage loss power is determined by the pressure difference and leakage flow at both ends of the impact piston. The calculation of the loss energy of the piston pair leakage can be expressed by :

$$
W_{L}=\int_{0}^{T} P_{L t} d t=\int_{0}^{T} \Delta p_{t} Q_{L t} d t
$$

where $W_{L}$ is the leakage loss of the impact piston pair in one cycle, $P_{L t}$ is the leakage power of the impact piston pair at time $t, \Delta p_{t}$ is the pressure difference between two ends of the impact piston pair at time $t$ determined by the working condition, $Q_{L t}$ is the leakage flow at time $t$, and $T$ is the motion cycle of hydraulic impactor with high frequency.

Leakage flow varies with the change of relative velocity between the impact piston and cylinder block. The impact piston and cylinder block are completely concentric, and the seal clearance is very small. Therefore, it can be regarded as concentric ring clearance. Under the conditions of the relative motion between the piston and the cylinder, the leakage flow is the flow of the hydraulic oil in the annular clearance. It can be calculated by the flow formula of the annular clearance:

$$
Q_{L t}=\frac{\pi d h_{t}^{3} \Delta p_{t}}{12 \eta l}+\frac{\pi d h_{t} v_{t}}{2}
$$

where $Q_{L t}$ is the leakage flow at time $t, d$ is the diameter of the impact piston, $h_{t}$ is the leakage clearance at time $t, \Delta p_{t}$ is the pressure difference between two ends of the impact piston pair at time $t$ determined by the working condition, $\eta$ is the dynamic viscosity of hydraulic oil, $l$ is the runner length, and $v_{i}$ is the relative velocity of the impact piston and cylinder block at time $t$.

The structure of the texture unit is both consistent and symmetrical. The leakage clearance at time $t$ can be approximated by the minimum film thickness of a texture element:

$$
h_{t}=\min h(x, y)
$$

where $h_{t}$ is the leakage clearance at time $t$, and $h(x, y)$ is the film thickness distribution function of texture units.

The cross section model of flow field for the control unit with cylindrical texture is shown in Fig. 4. In the figure, $v$ is the velocity of the impact piston, $h_{0}$ is the minimum initial clearance between cylinder block and impact piston, and $h_{g}$ is the height of the cylindrical texture element. Considering contact deformation under oil film pressure, the actual oil film thickness distribution function of the texture flow field can be expressed as follows:

$$
h(x, y)=\left\{\begin{array}{l}
h_{0}+h_{g}+\tau(x, y), x^{2}+y^{2} \leq r_{p}^{2} \\
h_{0}+\tau(x, y), x^{2}+y^{2}>r_{p}^{2}
\end{array}\right.
$$

where $h_{0}$ is the minimum initial clearance between the cylinder block and impact piston, $h_{g}$ is the height of the cylindrical texture element, $\tau(x, y)$ is the contact deformation, and $r_{p}$ is the radius of bottom surface of cylindrical texture element.

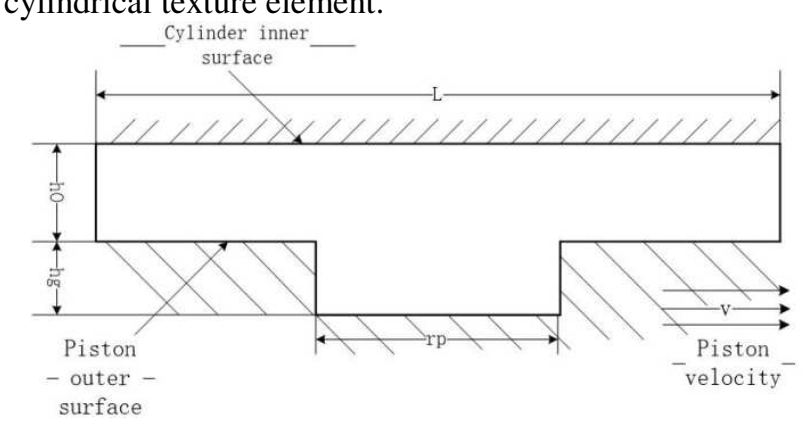

Fig. 4 Cross-section model of flow field for the control unit with cylindrical texture

$$
\tau(x, y)=\frac{2}{\pi E} \int_{0}^{L_{y}} \int_{0}^{L x} \frac{p(s, z)}{\sqrt{(x-s)^{2}+(y-z)^{2}}} d s d z
$$

where $\tau(x, y)$ is the contact deformation, $E$ is the equivalent elastic modulus, $p(s, z)$ is the oil film pressure, $L_{x}$ is the length of control unit along the $\mathrm{x}$-axis, and $L_{y}$ is the length of control unit along the y-axis.

\subsection{Friction loss calculation}

The friction loss power is determined by the friction force and the velocity of the impact piston. The equation for calculating the friction loss energy of the piston pair can be expressed by :

$$
W_{F}=\int_{0}^{T} P_{F t} d t=\int_{0}^{T} F_{f t} v_{t} d t
$$

where $W_{F}$ is the friction loss of the impact piston pair in one cycle, $P_{F t}$ is the friction power of impact piston pair at time $t, v_{i}$ is the relative velocity of the impact piston and cylinder block at time $t$ input according to experimental test data, $F_{f t}$ is the impact piston friction at time $t$, and $T$ is the motion cycle of the hydraulic impactor with high frequency.

Assuming that the friction produced by each texture unit is the same, the friction force to be applied to the impact piston at time $t$ can be expressed as:

$$
F_{f t}=K F_{f d t},
$$

where $F_{f t}$ is the impact piston friction applied to the impact 
piston at time $t, F_{f d t}$ is the friction produced by a single texture unit at time $t, K$ is the total number of texture units, $K=\frac{\pi d \ell}{L_{x} L_{y}}, d$ is the diameter of the impact piston, $l$ is the runner length, $L_{x}$ is the length of control unit along the $\mathrm{x}$-axis, and $L_{y}$ is the length of control unit along the y-axis.

The shearing force of oil causes the friction force of dynamic pressure oil film on a solid surface. According to Newton's internal friction theorem, the friction force of a single texture unit can be obtained by integrating the shear stress in the contact fluid layer along the control element.

$$
\mathrm{F}_{\mathrm{fd}}=\int_{0}^{\mathrm{L}_{\mathrm{x}}} \int_{0}^{\mathrm{L}_{\mathrm{y}}}\left(\frac{\mathrm{h}}{2} \frac{\partial \mathrm{p}}{\partial \mathrm{x}}+\frac{\mathrm{v \eta}}{\mathrm{h}}\right) \mathrm{dxdy}
$$

where $F_{f d}$ is the friction force of single texture unit of impact piston, $h$ is the oil film thickness, $p$ is the oil film pressure, $v$ is the relative velocity of the impact piston and cylinder block, $\eta$ is the dynamic viscosity of hydraulic oil, $L_{x}$ is the length of the control unit along the x-axis, and $L_{y}$ is the length of the control unit along the y-axis.

\subsection{Oil film pressure calculation for the textured impact piston pair}

Based on the previous assumptions and the formation mechanism of oil film pressure, the Reynolds equation of incompressible fluid under isothermal condition is written as [18]:

$$
\frac{\partial}{\partial x}\left(\rho h^{3} \frac{\partial p}{\partial x}\right)+\frac{\partial}{\partial y}\left(\rho h^{3} \frac{\partial p}{\partial y}\right)=6 \eta \frac{\partial}{\partial x}(v \rho h)
$$

where $\rho$ is the density of hydraulic oil, $h$ is the oil film thickness, $p$ is the oil film pressure, $\eta$ is the dynamic viscosity of hydraulic oil, and $v$ is the relative velocity of the impact piston and cylinder block.

The maximum working pressure is only $14 \mathrm{MPa}$ in the working condition of the high frequency hydraulic impact piston pair used in the hydraulic impactor. The effect of pressure on the density and viscosity of the hydraulic oil is very small under this range. Therefore, the change of oil density and viscosity is ignored and Eq. (11) can be simplified as:

$$
\frac{\partial}{\partial x}\left(h^{3} \frac{\partial p}{\partial x}\right)+\frac{\partial}{\partial y}\left(h^{3} \frac{\partial p}{\partial y}\right)=\wedge \frac{\partial h}{\partial x},
$$

where $\Lambda=6 v \eta_{0}$ is the simplified coefficient, $\eta_{0}$ is the initial dynamic viscosity of hydraulic oil, and $v$ is the relative velocity of the impact piston and cylinder block.

There is a certain height gradient on the textured surface, which contains the convergence wedge and divergence wedge. Assuming that the oil film pressure is periodically distributed, the Reynolds cavitations boundary condition in fluid lubrication can be written as:

$$
p(x, y) \geq 0, \text { and when } p(x, y)=0, \frac{d p}{d x}=0(13)
$$

Assuming that the pressure on both sides of the impact piston changes linearly, the single texture unit has a certain pressure drop, and the oil film boundary conditions can be obtained as follows:

$$
\Delta p=\frac{p_{i}-p_{0}}{M-1}, p(0, y)=p_{0}+\Delta p, p\left(L_{x}, y\right)=p_{0}
$$

where, $\Delta p$ is the pressure difference between two ends of the impact piston, $p_{i}$ is the supply oil pressure, $p_{0}$ is the return oil pressure, and $M$ is the number of nodes of the texture element along the $\mathrm{x}$-axis.

In addition, the oil film pressure distribution should satisfy the load balance equation, as shown in Eq. (15):

$$
F_{L}-\int_{0}^{L_{y}} \int_{0}^{L_{x}} p(x, y) d x d y=0
$$

where $F_{L}$ is the equivalent load, according to the boundary conditions $F_{L}=\frac{p_{i}+p_{0}}{2(M-1)} L_{x} L_{y}, \quad p_{i}$ is the supply oil pressure, $p_{0}$ is the return oil pressure, $M$ is the number of nodes of the texture element along the x-axis, $L_{x}$ is the length of control unit along the x-axis, and $L_{y}$ is the length of the control unit along the $y$-axis.

The oil film pressure is solved with boundary conditions according to Eq. (12). If the load balance equation is satisfied, the pressure distribution value of the texture unit can be obtained.

\section{Numerical solution of energy consumption model for textured impact piston pair with high frequency}

After determining the size of the texture unit, the length of the texture unit along the x-axis is divided into $M$ nodes, and the length of the texture unit along the $y$-axis is divided into $N$ nodes. According to Eq. (2), Eq. (3), and Eq. (8), the calculated step size is taken as $\Delta t$. The energy consumption in a cycle can be solved numerically by the following equation:

$$
W=\sum_{i=1}^{i=I+1} \Delta p_{i} Q_{i} \Delta t+\sum_{i=1}^{i=I+1} F_{f i} v_{i} \Delta t
$$

where $W$ is the energy consumption of the impact piston pair in one cycle, $I$ is the number of periods in a cycle $I=$ $T / \Delta t, T$ is the motion cycle of the hydraulic impactor with high frequency, $\Delta t$ is the calculated step size, $\Delta p_{i}$ is the pressure difference between two ends of the impact piston at time $i \times \Delta t, Q i$ is the leakage flow of hydraulic oil at time $i \times \Delta t, F_{f i}$ is the impact piston friction applied to the impact piston at time $i \times \Delta t$, and $v_{i}$ is the velocity of impact piston at time $i \times \Delta t$.

Combining Eq. (9) and Eq. (10), the friction force can be solved by using the composite trapezoid formula, 
which is shown as:

$$
F_{f t}=\frac{K_{x} L_{y}}{4(M-1)(N-1)} \sum_{j=1}^{N} \sum_{i=1}^{M}\left[\left(\frac{h_{i, j}}{2} \times \frac{p_{i+1, j}-p_{i, j}}{\Delta x}+\frac{\eta v_{i}}{h_{i, j}}\right) \times R_{i, j}\right]
$$

where $F_{f t}$ is the impact piston friction applied to the impact piston at time $t, K$ is the total number of texture units, $d$ is the diameter of the impact piston, $l$ is the runner length, $L_{x}$ is the length of the control unit along the x-axis, $L_{y}$ is the length of the control unit along the y-axis, $M$ is the number of nodes of the texture element along the x-axis, $N$ is the number of nodes of the texture element along the $\mathrm{y}$-axis, $h_{i, j}$ is the thickness of oil film at the intersection of $x$ direction node $i$ and y direction node $j, p_{i, j}$ s the pressure at the junction of $x$ direction node $i$ and $y$ direction node $j$, $\Delta x$ is the mesh length along the $\mathrm{x}$-axis, and $R_{i, j}$ is the coefficient matrix, which is written as:

$$
R_{i, j}=\left[\begin{array}{ccccc}
1 & 2 & \cdots & 2 & 1 \\
2 & 4 & \cdots & 4 & 2 \\
\vdots & \vdots & & \vdots & \vdots \\
2 & 4 & \cdots & 4 & 2 \\
1 & 2 & \cdots & 2 & 1
\end{array}\right]_{M \times N} .
$$

The contact deformation can be solved simply by the step function approximation method, that is:

$$
v_{i j}=\frac{2}{\pi E} \sum_{l=1}^{N} \sum_{k=1}^{M} C_{k l}^{i j} p_{k l}
$$

where $v_{i j}$ is the elastic deformation at the node $\left(x_{i}=\right.$ $\left.i \Delta x, y_{j}=j \Delta y\right)$, and $C_{k l}^{i j}$ is the deformation produced by the unit force of the node $\left(x_{k}=k \Delta x, y_{l}=l \Delta y\right)$ at the node $\left(x_{i}=i \Delta x, y_{j}=j \Delta y\right)$.

$$
\begin{aligned}
& C_{k l}^{i j}=|i-k|+0.5(|j-l|+0.5) \\
& \times\left\{(|i-k|+0.5) \ln \frac{f[(|j-l|+0.5) \Delta y,(|i-k|+0.5) \Delta x]}{f[(|j-l|-0.5) \Delta y,(|i-k|+0.5) \Delta x]} \Delta x\right. \\
& +(|i-k|-0.5) \ln \frac{f[(|j-l|-0.5) \Delta y,(|i-k|-0.5) \Delta x]}{f[(|j-l|+0.5) \Delta y,(|i-k|-0.5) \Delta x]} \Delta x \\
& +(|j-l|+0.5) \ln \frac{f[(|i-k|+0.5) \Delta x,(|j-l|+0.5) \Delta y]}{f[(|i-k|-0.5) \Delta x,(|j-l|+0.5) \Delta y]} \Delta y \\
& \left.+(|j-l|-0.5) \ln \frac{f[(|i-k|-0.5) \Delta x,(|j-l|-0.5) \Delta y]}{f[(|i-k|+0.5) \Delta x,(|j-l|-0.5) \Delta y]} \Delta y\right\}
\end{aligned}
$$

where $f(x, y)=x=\sqrt{x^{2}+y^{2}}, \Delta x=L_{x} /(M-1)$ is the mesh length along the $\mathrm{x}$-axis, and $\Delta y=L_{y} /(N-1)$ is the mesh length along the $y$-axis.

Using the difference solution method to manage Eq. (12), the iterative formula for calculating the pressure can be obtained:

$$
p_{i, j}^{k+1}=A p_{i+1, j}^{k}+B p_{i-1, j}^{k}+D p_{i, j+1}^{k}+F p_{i, j-1}^{k}+G
$$

where the band mark $k$ is the uncorrected pressure, the belt mark $k+l$ is the modified pressure, $i$ is the node number of the $x$ direction, $j$ is the node number of the $y$ direction, and $B, C, D, F, G$ is the calculated coefficient, which can be expressed in the following:

$$
\begin{aligned}
& B=\Delta y^{2} h_{i+1, j}^{3} /\left[\left(\Delta x^{2}+\Delta y^{2}\right)\left(h_{i+1, j}^{3}+h_{i, j}^{3}\right)\right] \\
& C=\Delta y^{2} h_{i, j}^{3} /\left[\left(\Delta x^{2}+\Delta y^{2}\right)\left(h_{i+1, j}^{3}+h_{i, j}^{3}\right)\right] \\
& D=\Delta x^{2} h_{i, j+1}^{3} /\left[\left(\Delta x^{2}+\Delta y^{2}\right)\left(h_{i+1, j}^{3}+h_{i, j}^{3}\right)\right] \\
& F=\Delta x^{2} h_{i, j}^{3} /\left[\left(\Delta x^{2}+\Delta y^{2}\right)\left(h_{i+1, j}^{3}+h_{i, j}^{3}\right)\right] \\
& G=\Lambda \Delta x \Delta y^{2}\left(h_{i+1, j}-h_{i, j}\right) /\left[\left(\Delta x^{2}+\Delta y^{2}\right)\left(h_{i+1, j}^{3}+h_{i, j}^{3}\right)\right],
\end{aligned}
$$

where $\Delta x$ is the mesh length along the $\mathrm{x}$-axis, $\Delta y$ is the mesh length along the y-axis, $i$ is the node number along the $\mathrm{x}$-axis, $j$ is the node number along the $\mathrm{y}$-axis, $h$ is the oil film thickness, $\Lambda=6 v \eta_{0}$ is the simplified coefficient, $\eta_{0}$ is the initial dynamic viscosity of hydraulic oil, and $v$ is the relative velocity of the impact piston and cylinder block.

In order to ensure the convergence of the calculation, the super relaxation iteration method is used to modify the algorithm, that is:

$$
p_{i, j}^{k+1}=\omega p_{i, j}^{k+1}+(1-\omega) p_{i, j}^{k}
$$

where $p$ is the oil film pressure, $i$ is the node number along the $\mathrm{x}$-axis, $j$ is the node number along the $\mathrm{y}$-axis, band mark $k$ is the uncorrected pressure, belt mark $k+1$ is the modified pressure, and $w$ is the relaxation iteration factor.

The convergence judgment is carried out with relative precision, as follows:

$$
\frac{\sum_{j=1}^{N} \sum_{i=1}^{M}\left|P_{i, j}^{k+1}-P_{i, j}^{k}\right|}{\sum_{j=1}^{N} \sum_{i=1}^{M} P_{i, j}^{k+1}} \leq \varepsilon .
$$

When the solution of oil film pressure is convergent, the impact piston friction applied to the impact piston can be calculated using Eq. (17) by the substitution of oil film pressure solved, and the energy consumption of the impact piston pair can be calculated according to Eq. (16). The specific solution process is presented in Fig. 5. 


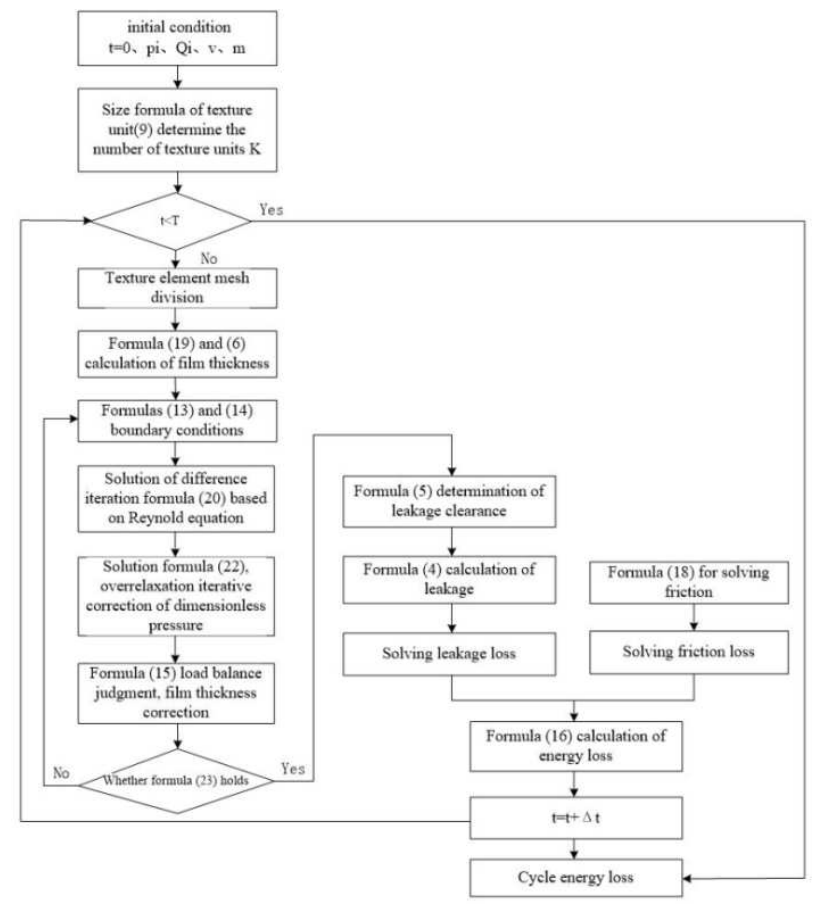

Fig. 5 Flow chart for solving energy consumption loss

\section{Energy consumption analysis of the textured impact piston pair with high frequency}

\subsection{Analysis parameter determination of an impact piston pair with high frequency}

The impact piston pair of the YG45 hydraulic impactor is taken as the analysis object. The working pressure and flow rate of the hydraulic impactor under rated working condition are constantly controlled by the system. The maximum impact velocity is obtained by strain method measurement using the test platform built by the excavator bucket arm and hydraulic oil source of excavator. The experiment is shown in Fig. 6. In the experiment, the supply oil pressure is set to $14 \mathrm{MPa}$, and the supply oil flow is set to $60 \mathrm{~L} / \mathrm{min}$. The test period of multi-channel high-speed waveform recorder is set to 50 $\mathrm{ms}$, and the data acquisition frequency is set to $1 \mathrm{MHz}$. The amplitude-frequency characteristic curve of the stress measured after the hydraulic impactor working stably is shown in Fig. 7. The maximum impact velocity of piston is $12.9 \mathrm{~m} / \mathrm{s}$, which was calculated by the stress wave theory according to the test stress in Fig. 7. The impact frequency is $74.8 \mathrm{~Hz}$, which was acquired from the amplitude-frequency characteristic curve of the stress. In other words, the motion cycle of hydraulic impactor with high frequency is $0.013 \mathrm{~s}$, with the specific parameters of the test system shown in Table 1. According to the hydraulic-mechanical coupling model of the hydraulic impactor under rated working condition [1], the velocity curve of the impact piston with high frequency under rated working condition is shown in Fig. 8. Fig. 8 shows that the piston stroke and return motion need a certain amount of time to reach the steady state, but they still show a periodic change. The reason for this is that the front and rear chamber pressures have not been established in the initial operation. Therefore, the velocity of the impact piston can be taken as the velocity value of the impact piston in any period after stable operation. The pressure and flow parameters of the energy consumption analysis model can be set as the same values of the adjusted system. Specific parameters are as follows: the maximum motion velocity of the piston is $12.9 \mathrm{~m} / \mathrm{s}$, the oil supply pressure is $14 \mathrm{MPa}$, the oil return pressure is $0.4 \mathrm{MPa}$, and the motion cycle of hydraulic impactor is $0.013 \mathrm{~s}$.

Table 1 Specific parameters of the test system

\begin{tabular}{c|c}
\hline $\begin{array}{c}\text { Supply pressure } \\
\text { Ambient pressure }\end{array}$ & $0.101 \mathrm{MPa}$ \\
\hline $\begin{array}{c}\text { System flow } \\
\text { recorder }\end{array}$ & $60 \mathrm{~L} / \mathrm{min}$ \\
\hline $\begin{array}{c}\text { Data acquisition frequency } \\
\text { Maximum velocity of } \\
\text { impact piston }\end{array}$ & $50 \mathrm{~ms}$ \\
\hline Impacting frequency & $14 \mathrm{MHz}$ \\
\hline potion cycle of impact \\
piston
\end{tabular}

Fig. 6 Testing system of the YG45 hydraulic impactor 


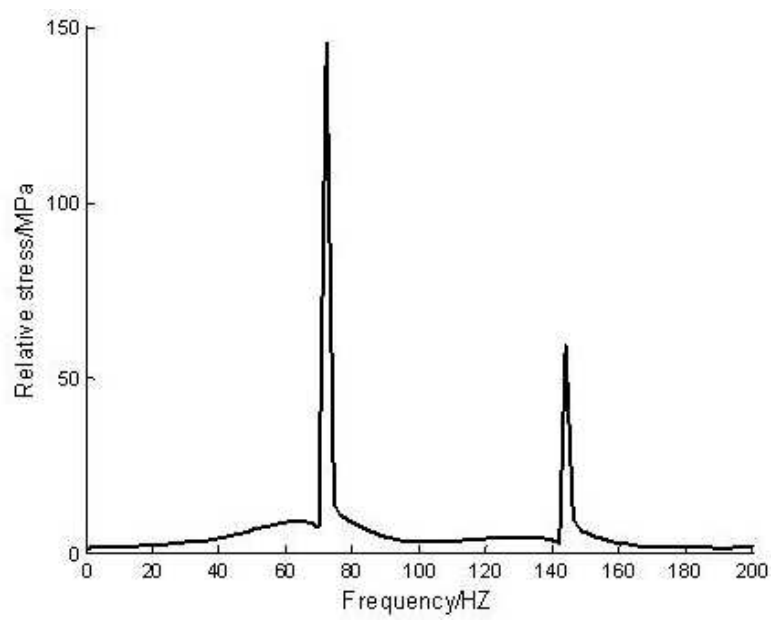

Fig. 7 Amplitude-frequency characteristic curve of stress

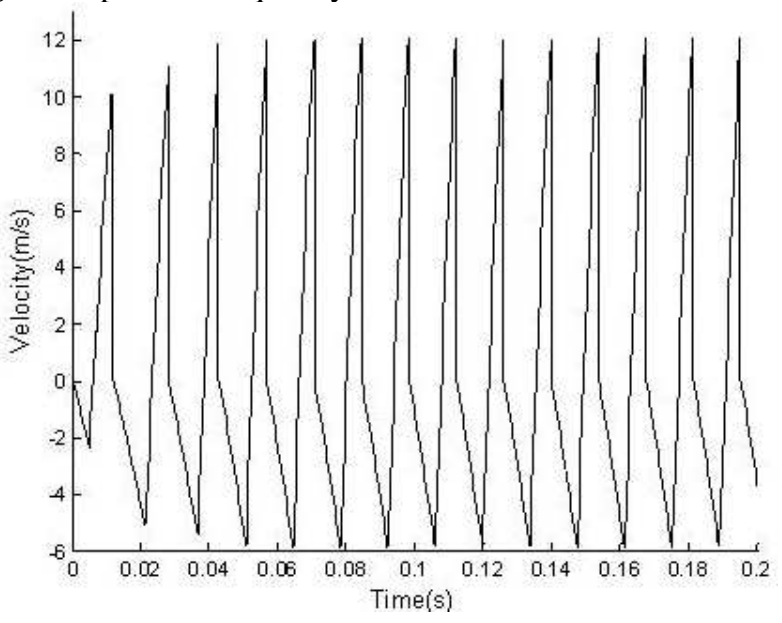

Fig. 8 Velocity curve of the impact piston under rated working condition

\subsection{Energy consumption analysis of the texture impact piston pair}

A cylindrical texture unit is arranged on the surface of the impact piston. The length of the control unit along the $\mathrm{x}$-axis $L_{x}$ is $1.5 \mathrm{~mm}$, and the length of the control unit along the $y$-axis $L_{y}$ is $1.5 \mathrm{~mm}$. The area ratio textured is $30 \%$, the dynamic viscosity of the hydraulic oil used is $0.06 P_{a} \cdot s$, the initial oil film thickness is $27.5 \mu$ $\mathrm{m}$, and the depth of cylindrical texture is $27.5 \mu \mathrm{m}$. The energy consumption model of the impact piston pair is calculated using MATLAB. The oil film thickness and pressure drop of the first element near the front cavity at maximum velocity in return travel are shown in Fig. 9 and Fig. 10, respectively. Through Fig. 9 and Fig. 10, it can be observed that the cylindrical texture surface can produce hydrodynamic pressure and form hydrodynamic pressure lubrication film. The hydrodynamic lubrication effect of texture under full oil film lubrication will significantly improve the bearing capacity of the surface, and it will have better dynamic pressure lubrication performance than the non-textured surface. In addition, the area where the pressure peak is located is on the right side of the opening area. This is due to the fact that the left side of the divergent wedge and the right side of the convergence wedge having lower pressure during the movement of the textured piston pair. Therefore, the pressure reaches the maximum on the right side of the opening region.

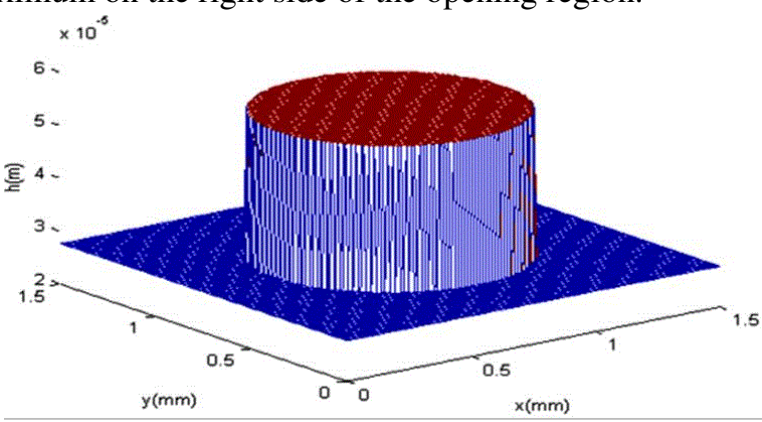

Fig. 9 Oil film thickness on textured surface

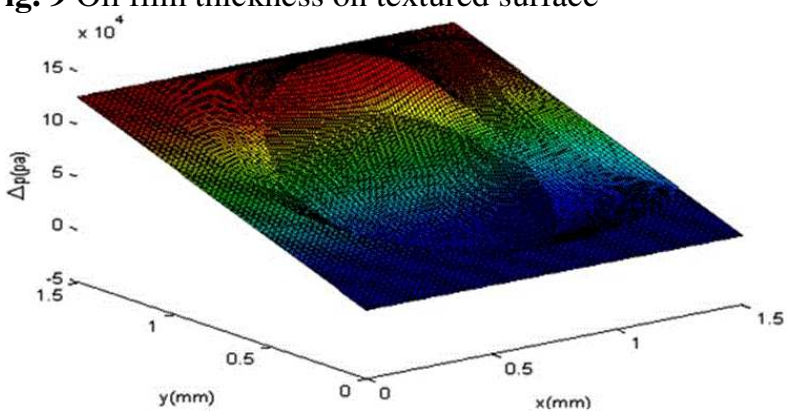

Fig. 10 Pressure drop of the first element near the front cavity at maximum backhaul velocity

The comparison of energy consumption between the non-textured impact piston pair and cylindrical textured impact piston pair using calculation results is shown in Fig. 11. The results show that the energy consumption of the cylindrical textured impact piston pair is $14.63 \mathrm{~J}$ in one cycle under the above parameters. Compared with the non-textured impact piston pair, the ratio of energy consumption to total energy loss is reduced by $5.88 \%$. The surface friction force greatly reduces with the cylindrical texture, and the reduction of surface friction greatly improves the friction performance of the surface and significantly reduces friction loss. In addition, the leakage loss slightly increases with the cylindrical texture. However, the increased leakage loss can be ignored compared with the reduced friction loss. The cylindrical texture noticeably reduces the energy consumption of the impact piston in general. The energy consumption of the impact piston pair is $18.24 \mathrm{~J}$ and the ratio of energy consumption to total energy loss of the hydraulic impactor is $29.77 \%$. Therefore, reducing the energy consumption of the impact piston pair can significantly improve the energy utilization rate of hydraulic impactor. 


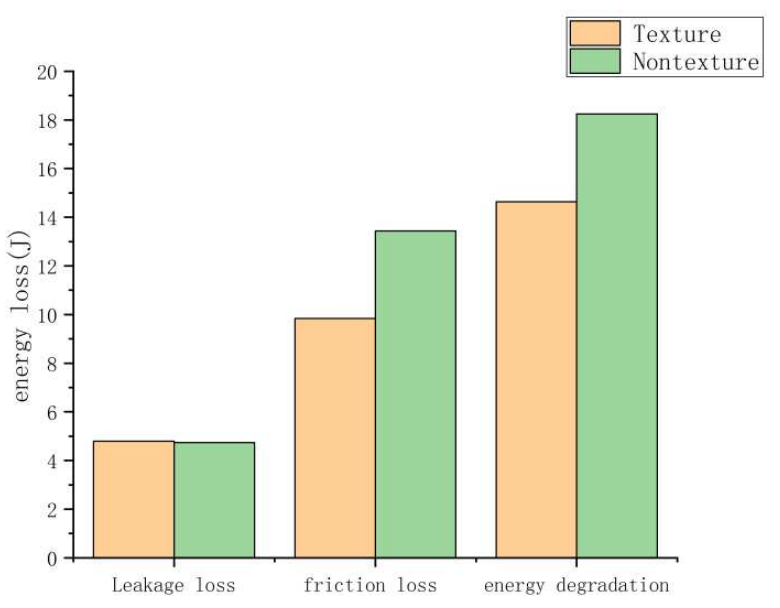

Fig. 11 Comparison of energy consumption between the non-textured impact piston pair and cylindrical textured impact piston pair

\subsection{Effects of area ratio textured to energy consumption of the impact piston}

The control unit is square. Limited by the shape of the control unit, the maximum area ratio textured using cylindrical texture can only reach $78.5 \%$. The thickness of oil film is set to $27.5 \mu \mathrm{m}$, and the depth of cylindrical texture is set to $27.5 \mu \mathrm{m}$. The energy consumption and energy consumption ratio to total energy loss of the impact piston pair in one cycle with different area ratios textured are shown in Table 1. The energy consumption of the non-textured impact piston pair is $18.24 \mathrm{~J}$. When the cylindrical texture is used, the energy consumption is reduced regardless of the area ratio textured, which is caused by the decline of friction loss. The energy consumption of the impact piston pair with different area ratios textured is shown in Fig. 10. As can be seen from the figure, the energy consumption of the impact piston with cylindrical texture is smaller than that without texture. The energy consumption of the impact piston first decreases and then remains unchanged with the increase of area ratio textured. The energy consumption ratio of the impact piston pair to total energy loss with different area ratios textured is shown in Fig. 11. It can be seen that the energy consumption ratio decreased by $1.32 \%$ to $10.98 \%$ with the area ratio textured ranging from 0.1 to 0.78 . The decrease in energy consumption ratio reveals a trend of first accelerating and then slowing down. The energy consumption ratio reaches the minimum before the area ratio textured achieves the maximum, and the energy consumption ratio can be reduced to the lowest when the area ratio textured is in the range of 0.64 to 0.70 .

Table 2 Energy consumption and energy consumption ratio of the impact piston pair in one cycle with different area ratios textured

\begin{tabular}{|c|c|c|c|c|c|c|c|c|c|}
\hline $\begin{array}{c}\text { Area } \\
\text { ratio } \\
\text { textured }\end{array}$ & 0 & $\begin{array}{c}0 \\
.1\end{array}$ & $\begin{array}{c}0 \\
.2\end{array}$ & $\begin{array}{r}0 \\
.25\end{array}$ & $\begin{array}{c}0 \\
.3\end{array}$ & $\begin{array}{r}0 \\
.35\end{array}$ & $\begin{array}{l}0 \\
.4\end{array}$ & $\begin{array}{c}0 \\
.5\end{array}$ & $\begin{array}{c}0 \\
.6\end{array}$ \\
\hline Energy & 1 & 1 & 1 & 1 & 1 & 1 & 1 & 1 & 1 \\
\hline consump & 8.2 & 7.4 & 6.2 & 5.4 & 4.6 & 3.3 & 2.6 & 1.9 & 1.6 \\
\hline tion/J & 4 & 3 & 1 & 8 & 3 & 8 & 4 & 1 & 0 \\
\hline \multirow{3}{*}{$\begin{array}{c}\text { Energy } \\
\text { consump } \\
\text { tion } \\
\text { ratio/\% }\end{array}$} & 2 & 2 & 2 & 2 & 2 & 2 & 2 & 1 & 1 \\
\hline & 9.7 & 8.4 & 6.4 & 5.2 & 3.8 & 1.8 & 0.6 & 9.4 & 8.9 \\
\hline & 7 & 4 & 5 & 6 & 7 & 3 & 3 & 4 & 3 \\
\hline $\begin{array}{l}\text { Area } \\
\text { ratio }\end{array}$ & 0 & 0 & 0 & 0 & 0 & 0 & 0 & & \\
\hline $\begin{array}{c}\text { textured/ } \\
\%\end{array}$ & .62 & .64 & .66 & .68 & .7 & .75 & .78 & & \\
\hline Energy & 1 & 1 & 1 & 1 & 1 & 1 & 1 & & \\
\hline consump & 1.5 & 1.5 & 1.5 & 1.5 & 1.5 & 1.5 & 1.5 & & \\
\hline tion/J & 6 & 4 & 2 & 1 & 1 & 1 & 1 & & \\
\hline \multirow{3}{*}{$\begin{array}{c}\text { Energy } \\
\text { consump } \\
\text { tion } \\
\text { ratio/\% }\end{array}$} & 1 & 1 & 1 & 1 & 1 & 1 & 1 & & \\
\hline & 8.8 & 8.8 & 8.8 & 8.7 & 8.7 & 8.7 & 8.7 & & \\
\hline & 6 & 3 & 0 & 8 & 8 & 8 & 8 & & \\
\hline
\end{tabular}

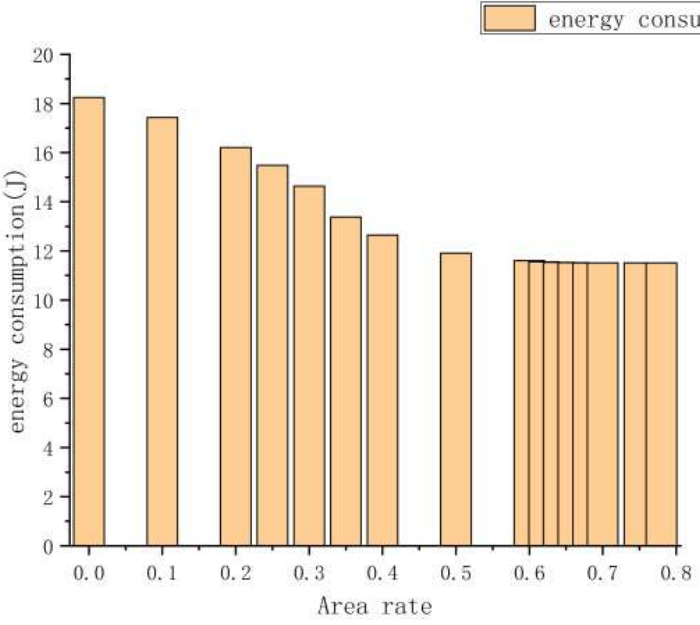

Fig. 12 Energy consumption of the impact piston pair with different area ratios textured

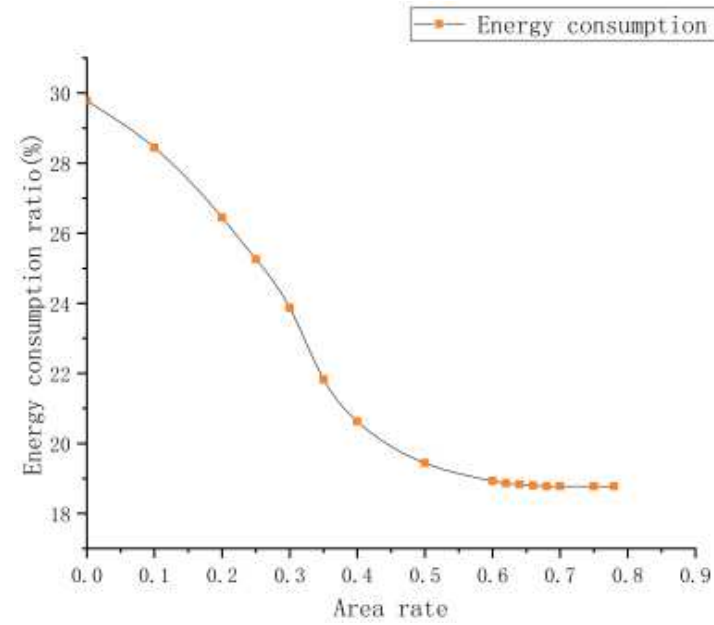


Fig. 13 Energy consumption ratio of the impact piston pair with different area ratios textured

\subsection{Effects of depth ratio textured to the energy consumption of impact piston}

As shown in Fig. 4, depth ratio textured is defined as the ratio of the height of the cylindrical texture element to the minimum initial clearance between the cylinder block and impact piston. The thickness of oil film is set to 27.5 $\mu \mathrm{m}$. The energy consumption and energy consumption ratio to total energy loss of the impact piston pair in one cycle with different depth ratios textured under area ratios textured ranging from 0.3 to 0.5 are shown in Tables $2-4$. When the cylindrical texture is used, the energy consumption is reduced regardless of the depth ratio textured under a certain area ratio textured. Energy consumption of the impact piston pair with different depth ratios textured under varying area ratios textured is shown in Fig. 12. As can be seen from the figure, the energy consumption of impact piston first decreases and then increases with the increase of depth ratio textured. Energy consumption ratio of the impact piston pair with different depth ratios textured under varying area ratios textured is shown in Fig. 13. It can be seen that energy consumption ratio decreased by $3.21 \%$ to $5.68 \%$ with the depth ratio textured ranging from 0.3 to 1.3 , and the energy consumption ratio can be reduced to the lowest when the depth ratio textured is in the range of 1 to 1.1 .

Table 3 Energy consumption and energy consumption ratio of the impact piston pair in one cycle with different depth ratios textured when the area ratio textured is 0.3

\begin{tabular}{crrrrrr}
\hline $\begin{array}{c}\text { Depth } \\
\text { ratio }\end{array}$ & 0. & 0. & 0. & 0. & 1. & 1. \\
textured & 3 & 5 & 7 & 9 & 1 & 3 \\
\hline $\begin{array}{c}\text { Energy } \\
\text { consumption }\end{array}$ & 1 & 1 & 1 & 1 & 1 & 1 \\
$/ \mathrm{J}$ & 6.27 & 5.54 & 5.07 & 4.76 & 4.80 & 5.12 \\
$\begin{array}{c}\text { Energy } \\
\text { consumption }\end{array}$ & 2 & 2 & 2 & 2 & 2 & 2 \\
ratio/\% & 6.55 & 5.36 & 4.59 & 4.09 & 4.15 & 4.67 \\
\hline
\end{tabular}

Table 4 Energy consumption and energy consumption ratio of the impact piston pair in one cycle with different depth ratios textured when the area ratio textured is 0.4

\begin{tabular}{ccccccc}
\hline Depth & 0. & 0. & 0. & 0. & 1. & 1. \\
ratio & 3 & 5 & 7 & 9 & 1 & 3 \\
textured & & & & & & \\
\hline Energy & 1 & 1 & 1 & 1 & 1 & 1 \\
\hline
\end{tabular}

\begin{tabular}{crrrrrr}
\hline $\begin{array}{c}\text { consumption } \\
/ \mathrm{J}\end{array}$ & 5.59 & 4.45 & 3.59 & 2.93 & 2.39 & 3.15 \\
$\begin{array}{c}\text { Energy } \\
\text { consumption }\end{array}$ & 2 & 2 & 2 & 2 & 2 & 2 \\
ratio/\% & 5.44 & 3.58 & 2.18 & 1.10 & 0.22 & 1.46 \\
\hline
\end{tabular}

Table 5 Energy consumption and energy consumption ratio of the impact piston pair in one cycle with different depth ratios textured when the area ratio textured is 0.5

\begin{tabular}{crrrrrr}
\hline $\begin{array}{c}\text { Depth } \\
\text { ratio }\end{array}$ & 0. & 0. & 0. & 0. & 1. & 1. \\
textured & 3 & 5 & 7 & 9 & 1 & 3 \\
\hline $\begin{array}{c}\text { Energy } \\
\text { consumption }\end{array}$ & 1 & 1 & 1 & 1 & 1 & 1 \\
$/ \mathrm{J}$ & 5.30 & 4.00 & 3.02 & 2.24 & 1.98 & 2.68 \\
$\begin{array}{c}\text { Energy } \\
\text { consumption }\end{array}$ & 2 & 2 & 2 & 1 & 1 & 2 \\
ratio/\% & 4.97 & 2.85 & 1.25 & 9.97 & 9.55 & 0.69 \\
\hline
\end{tabular}

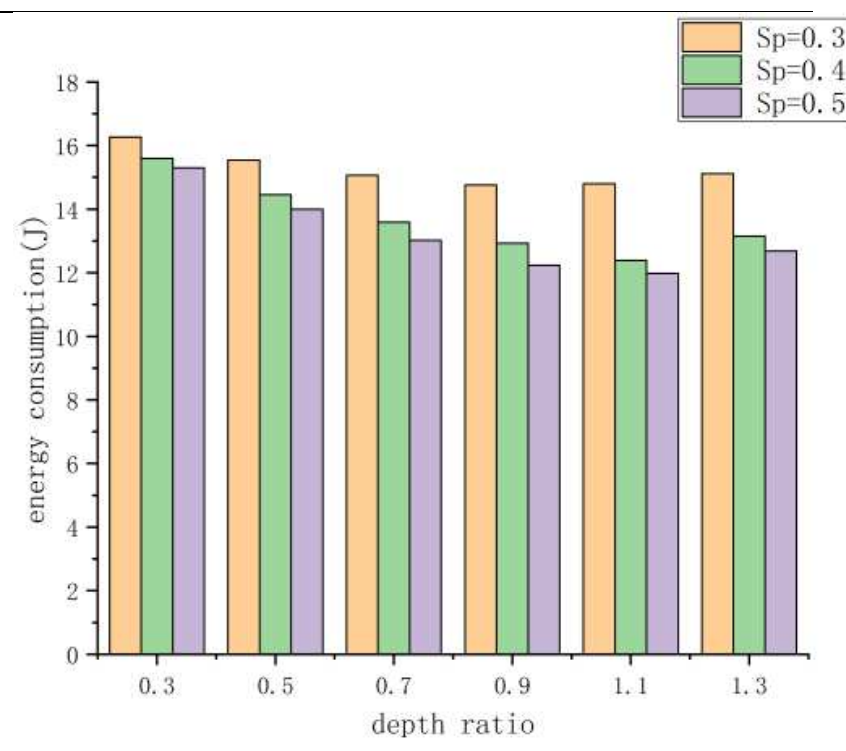

Fig. 14 Energy consumption of the impact piston pair with different depth ratios textured under varying area ratios textured 


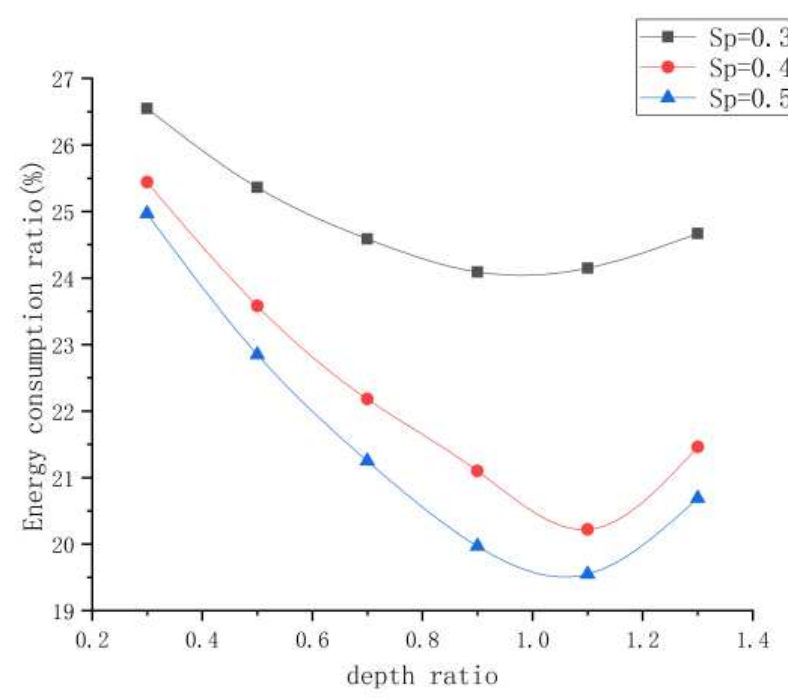

Fig. 15 Energy consumption ratio of the impact piston pair with different depth ratios textured under varying area ratios textured

The addition of a cylindrical microtexture can improve lubrication performance, reduce energy consumption, and increase the local oil film thickness. With the increase of oil film thickness, the shear rate of oil decreases, leading to the decrease of friction and the energy consumption of the piston pair. The above analysis also shows that different area ratios and depth ratios of texture have an influence on the reduction of energy consumption. Minimizing the energy consumption of the piston pair can be achieved by changing the area ratio and depth ratio of the cylindrical microtexture, which improves the energy utilization rate of the hydraulic impactor.

\section{Conclusions}

According to the characteristics of reciprocating periodic motion with high frequency, the energy consumption analysis model of the textured piston pair is established. The model is used to analyze the energy consumption of the impact piston pair of the YG45 hydraulic impactor. The results show that:

(1) The energy consumption of the impact piston pair accounts for $29.77 \%$ of the total energy loss of the hydraulic impactor. It is an effective way to improve the energy utilization rate of the hydraulic impactor by reducing the energy consumption of the impact piston pair.

(2) Energy consumption of the impact piston pair with cylindrical texture is reduced regardless of the area ratio textured. Energy consumption ratio decreased by $1.32 \%$ to $10.98 \%$ with the area ratio textured ranging from 0.1 to 0.78 , and energy consumption ratio can be reduced to the lowest when the area ratio textured is in the range of
0.64 to 0.70 .

(3) Energy consumption of the impact piston pair with cylindrical texture is also reduced regardless of the depth ratio textured, though the value is only slightly reduced. The energy consumption ratio decreased by $3.21 \%$ to $5.68 \%$ with the depth ratio textured ranging from 0.3 to 1.3 , and the energy consumption ratio can be reduced to its lowest when the depth ratio textured is in the range of 1 to 1.1 .

\section{Declaration}

\section{Acknowledgements:}

The authors sincerely thanks to Professor Yong Guo of Hunan University of Science and Technology for his critical discussion and reading during manuscript preparation.

\section{Funding}

Supported by National Natural Science Foundation of China (No.51705147,No.51809091,No.51779092) and Hunan Provincial Natural Science Foundation of China (No.2018JJ3182), and Scientific Research Fund of Hunan Provincial Education Department (19B191).

\section{Availability of data and materials}

The datasets supporting the conclusions of this article are included within the article.

\section{Authors' contributions}

The author' contributions are as follows: Yong Guo and Yanping $\mathrm{Hu}$ was in charge of the whole trial; $\mathrm{Hu} \mathrm{Mo}$ and Song Quan wrote the manuscript; Zhewu Chen assisted with sampling and laboratory analyses.

\section{Competing interests}

The authors declare no competing financial interests.

\section{Consent for publication \\ Not applicable}

\section{Ethics approval and consent to participate} Not applicable

\section{Reference:}

[1] Yong G, Deshun L, Shuyi Y, et al. Hydraulic-mechanical coupling modeling by bond graph for impact system of a high frequency rock drill drifter with sleeve distributor[J]. Automation in Construction, 2016, 63: 88-99. 
[2] Saffet Yagiz,Halil Karahan. Application of various optimization techniques and comparison of their performances for predicting TBM penetration rate in rock mass[J]. International Journal of Rock Mechanics and Mining Sciences,2015,80.

[3] Oh J Y, Lee G H, Kang H S, et al. Modeling and performance analysis of rock drill drifters for rock stiffness[J]. International Journal of Precision Engineering and Manufacturing, 2012, 13(12): 2187-2193.

[4] Seo J, Noh D K, Lee G H, et al. A percussion performance analysis for rock-drill drifter through simulation modeling and experimental validation[J]. International Journal of Precision Engineering and Manufacturing, 2016, 17(2): 163-170.

[5] Flegner P, Kačur J, Durdán M, et al. Significant damages of core diamond bits in the process of rocks drilling[J]. Engineering failure analysis, 2016, 59: 354-365.

[6] Wang X., Yamaguchi A. Characteristics of hydrostatic bearing/seal parts for water hydraulic pumps and motors. Part 1: Experiment and theory[J]. Tribology international,2002, 35(7): 425-433.

[7] Yingna Liang,Dianrong Gao,Bo Chen,Jianhua Zhao. Friction and Wear Study on Friction Pairs with a Biomimetic Non-smooth Surface of $316 \mathrm{~L}$ Relative to CF/PEEK under a Seawater Lubricated Condition[J]. Chinese Journal of Mechanical Engineering,2019,32(1).

[8] Tang Yong, Tang Heng, Wan Zhenping, Yuan Wei, Lu Longsheng, Li Zongtao. Research Progress of Surface texture hydrodynamic Lubrication [J]. Journal of South China University of Technology (Natural Science Edition), 2017 (09): 1-11.

[9]Nanbu T, Ren N, Yasuda Y, et al. Micro-textures in concentrated conformal-contact lubrication: effects of texture bottom shape and surface relative motion[J]. Tribology Letters, 2008, 29(3): 241-252.

[10] Zhang J, Chen Y, Xu B, et al. Effect of surface texture on wear reduction of the tilting cylinder and the valve plate for a high-speed electro-hydrostatic actuator pump[J]. Wear, 2018, 414: 68-78.

[11]?zkan ?zmen,Cem Sinano?lu,Abdullah Caliskan,Hasan Badem.Prediction of Leakage from an Axial Piston Pump Slipper with Circular Dimples Using Deep Neural Networks[J].Chinese Journal of Mechanical Engineering,2020,33(02):119-129.

[12] Bifeng Y, Yanqiang Q, Shao S, et al. Synergistic lubrication effect of cylinder liner surface texture on diesel engine [J]. Journal of Internal Combustion engines, 2014N 32 (02): 178-185.

[13] Chen Y, Zhang J, Xu B, et al. Multi-objective optimization of micron-scale surface textures for the cylinder/valve plate interface in axial piston pumps[J]. Tribology International, 2019.

[14] Uddin M S, Liu Y W. Design and optimization of a new geometric texture shape for the enhancement of hydrodynamic lubrication performance of parallel slider surfaces[J]. Biosurface and Biotribology, 2016, 2(2): 59-69.

[15] Gropper D, Harvey T J, Wang L. Numerical analysis and optimization of surface textures for a tilting pad thrust bearing $[\mathrm{J}]$. Tribology International, 2018, 124: 134-144.

[16] Wang X, Wang J, Zhang B, et al. Design principles for the area density of dimple patterns[J]. Proceedings of the Institution of Mechanical Engineers, Part J: Journal of Engineering Tribology, 2015, 229(4): 538-546.

[17] Ying Z, Guang Y, Yang M, et al. Theoretical study on dynamic Lubrication performance of Micro-textured Surface of hydraulic cylinder Piston [J]. Journal of Wuhan University of Science and Technology, 2017, 40 (01): 55-60.

[18] Mohammad Jalal Ahammad, Mohammad Azizur Rahman, Jahrul Alam, et al. A computational fluid dynamics investigation of the flow behavior near a wellbore using three-dimensional Navier-Stokes equations. 2019, 11(9)

\section{Biographical notes}

Hu Mo, born in 1985 , is currently a PhD candidate at Hunan Provincial Key Laboratory of Health Maintenance for Mechanical Equipment, Hunan University of Science and Technology, China.

E-mail: 18229849289@163.com

Yong Guo, born in 1985, is currently a professor at Hunan University of Science and Technology, China. He received his master degree in Zhongnan University, China.

E-mail: hnkjdx_guoy@163.com

Yanping Hu, born in 1957, is currently a professor at Hunan University of Science and Technology, China. He received his master degree in Zhongnan University, China.

E-mail: yphu@ @unst.edu.cn

Song Quan, born in 1997, is currently a master candidate at Hunan Provincial Key Laboratory of Health Maintenance for Mechanical Equipment, Hunan University of Science and Technology, China.

E-mail: hnust_qs0425@163.com.

Zhewu Chen, born in 1984, is currently an professor at Hunan University of Science and Technology, China. He received his $\mathrm{PhD}$ degree from Hunan Universtiy, China.

E-mail: 258269681@qq.com 


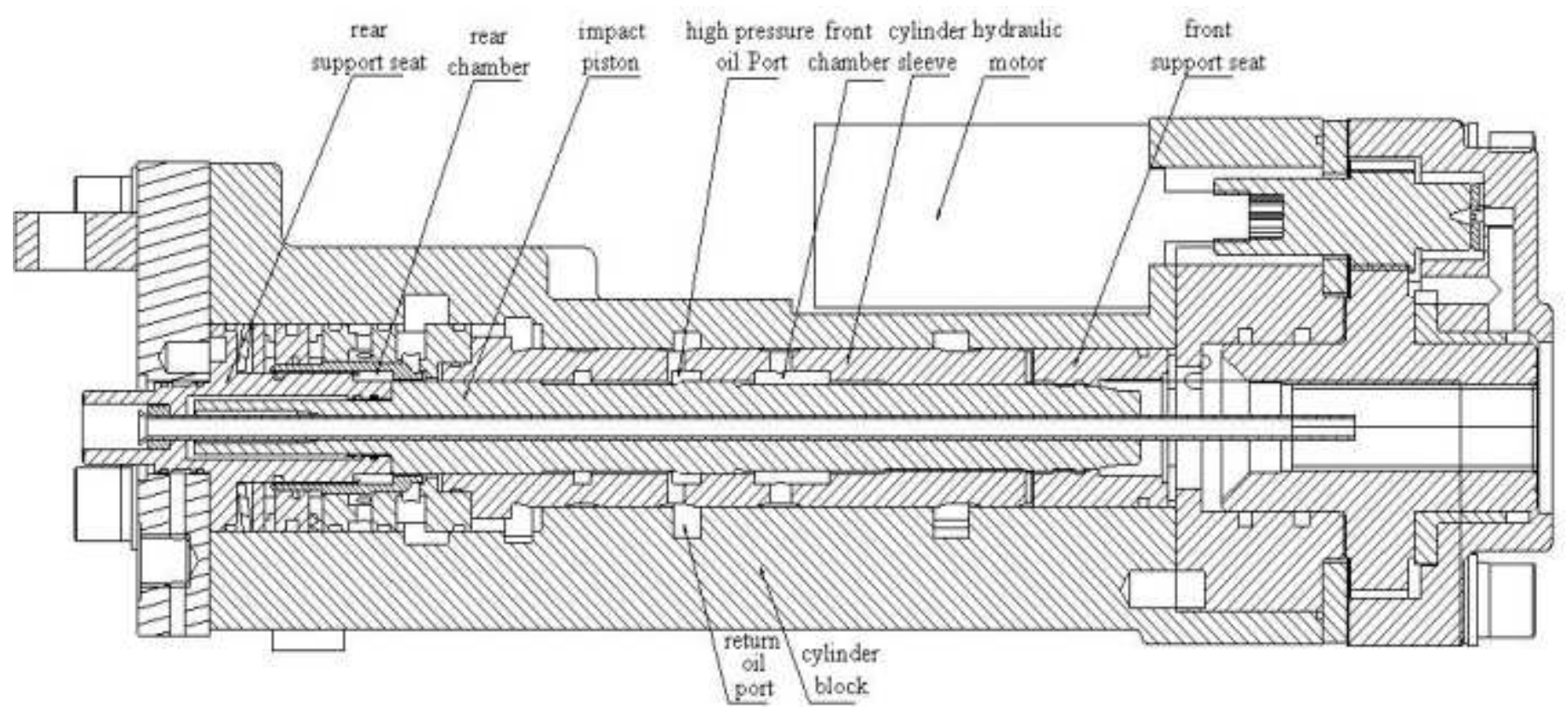

Figure 1

Impact mechanism of the YG45 hydraulic rock drill

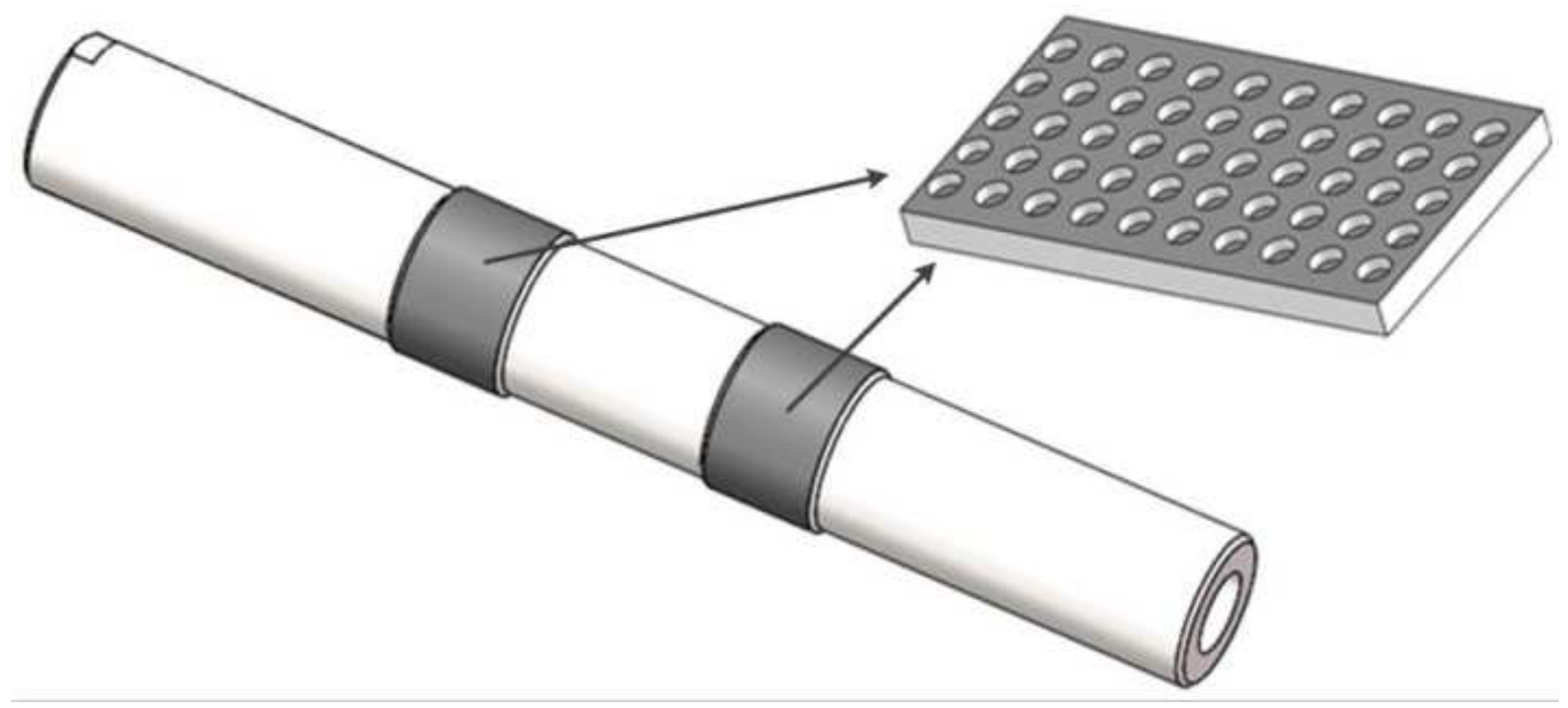

\section{Figure 2}

Cylindrical texture geometric model of the impact piston surface 


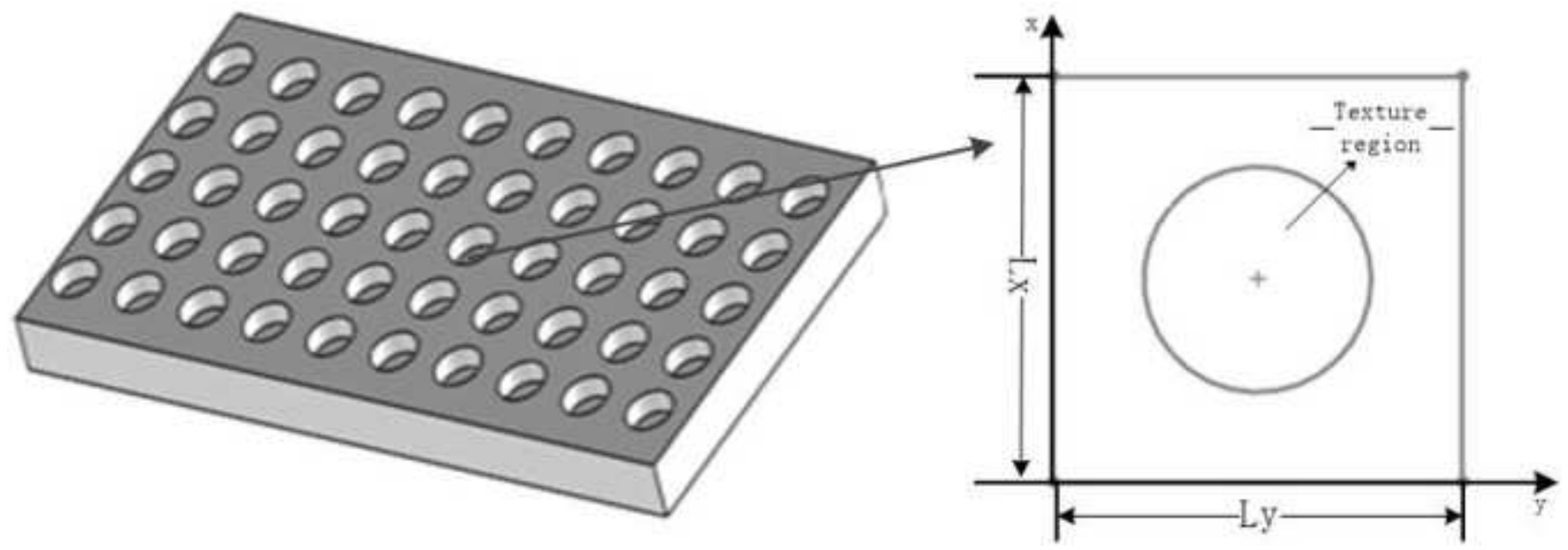

Figure 3

Geometric model of the texture control unit

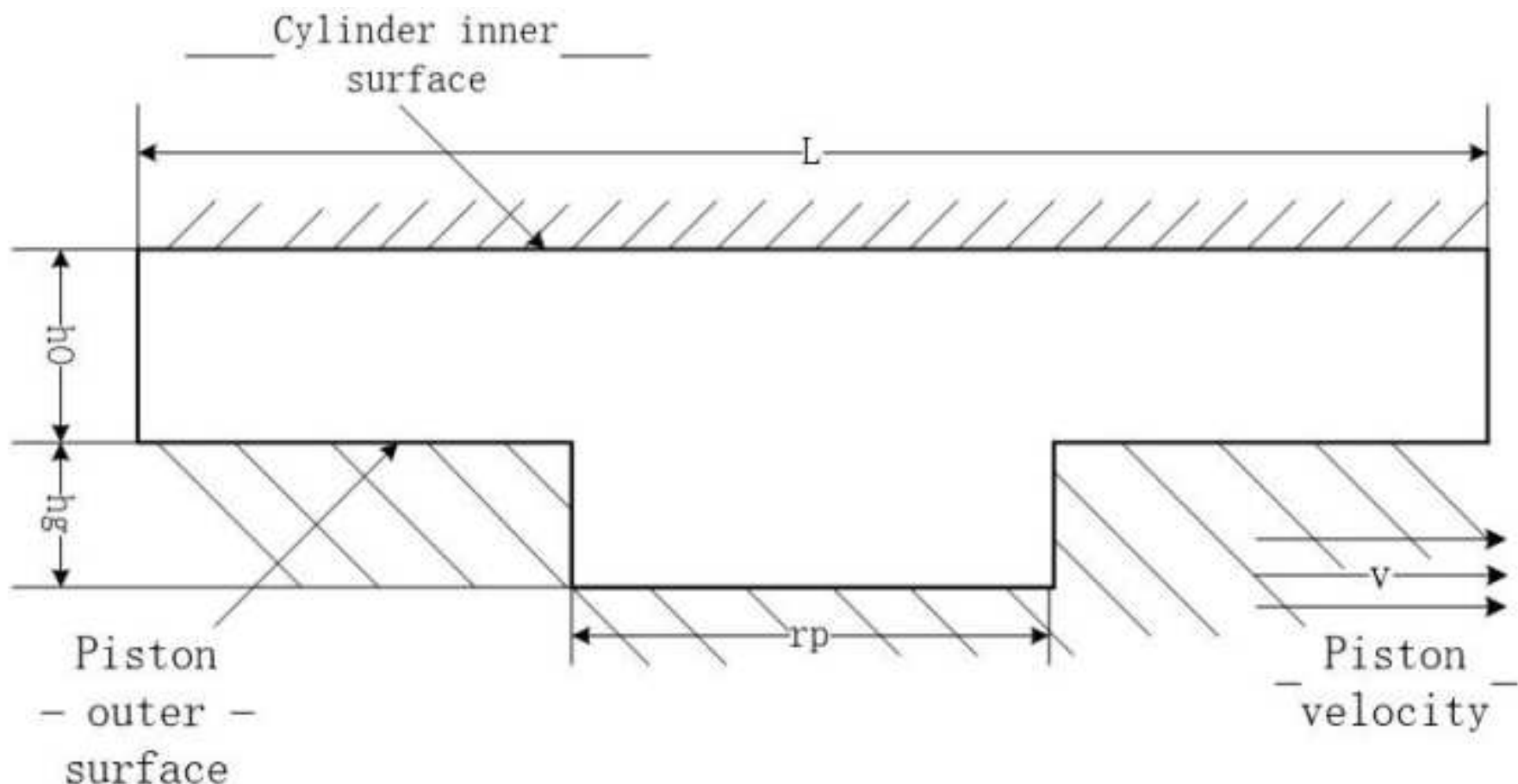

Figure 4

Cross-section model of flow field for the control unit with cylindrical texture 


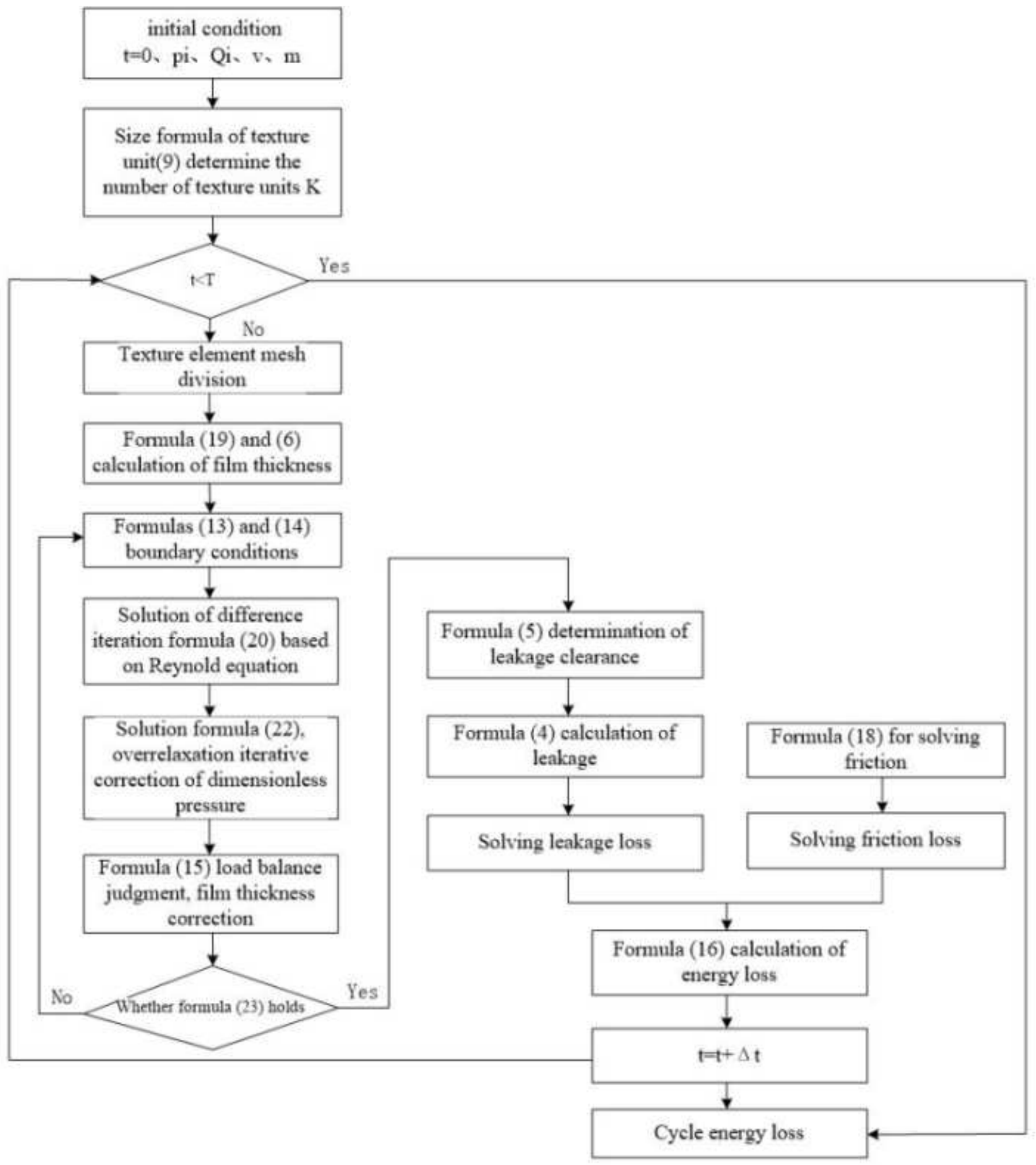

Figure 5

Flow chart for solving energy consumption loss 


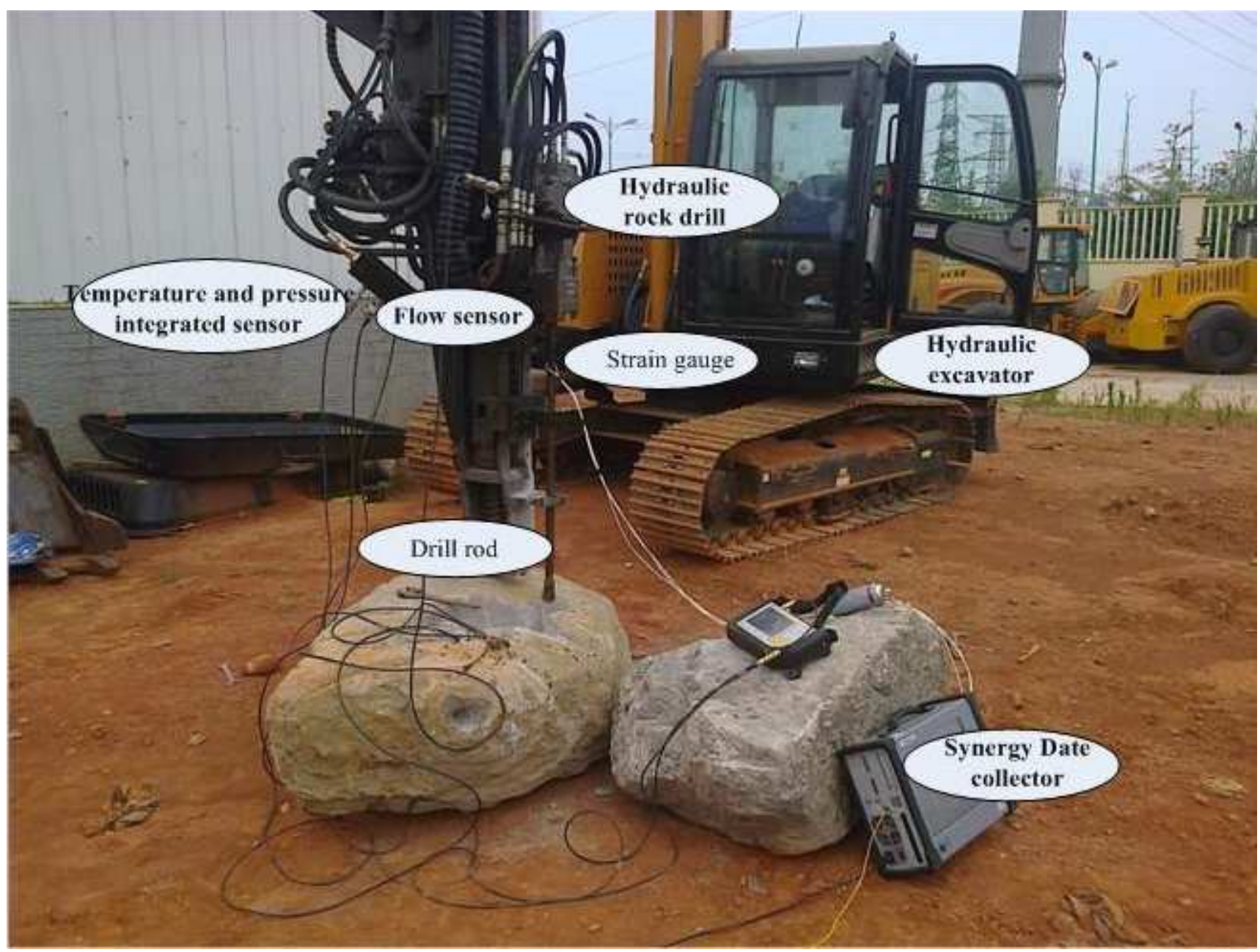

Figure 6

Testing system of the YG45 hydraulic impactor

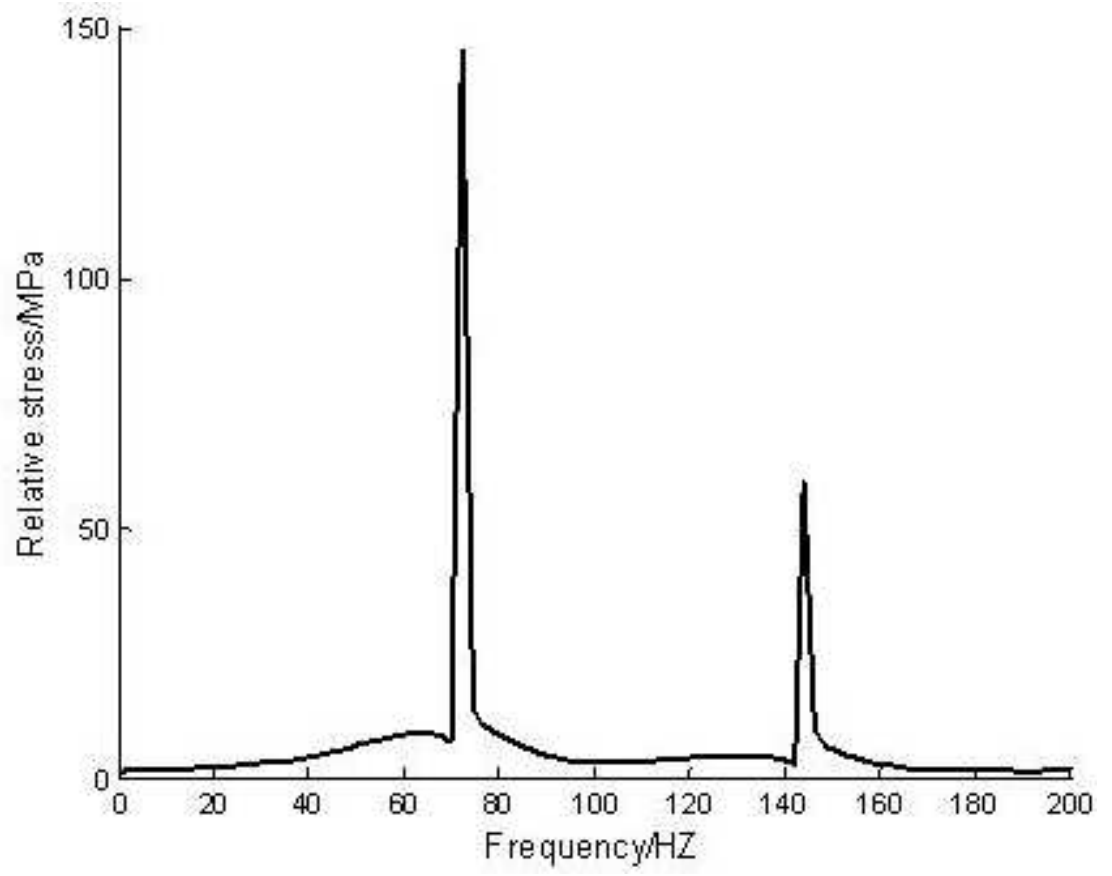

Figure 7 
Amplitude-frequency characteristic curve of stress

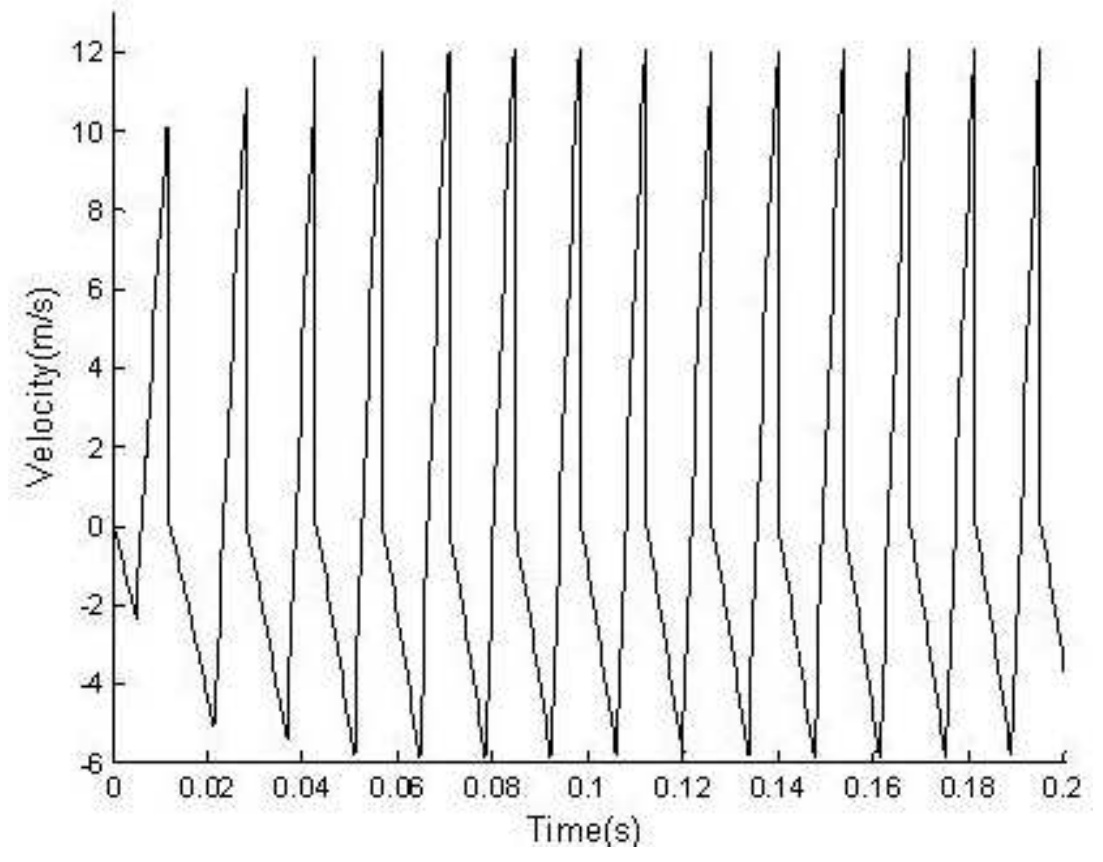

Figure 8

Velocity curve of the impact piston under rated working condition

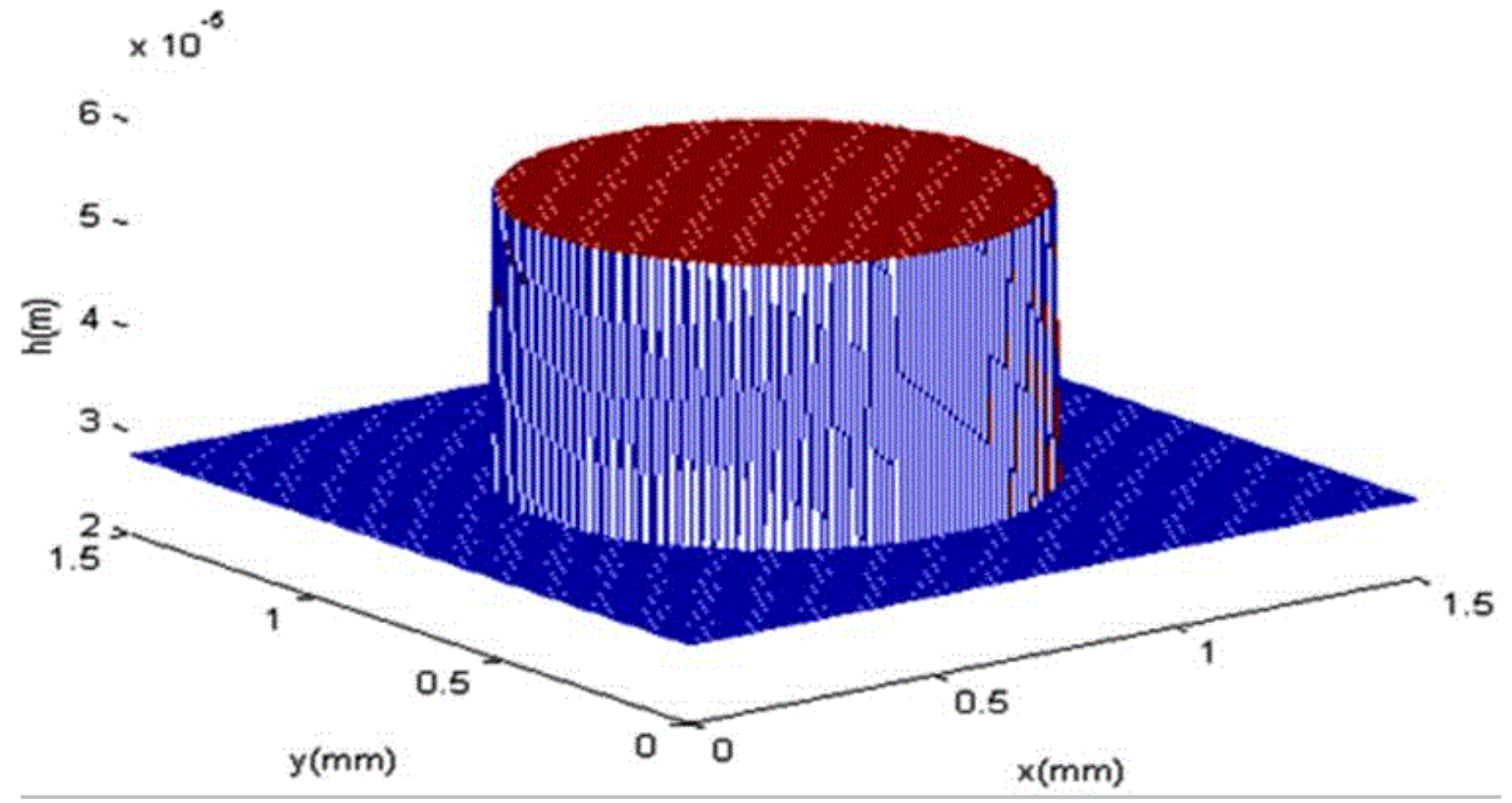

Figure 9

Oil film thickness on textured surface 


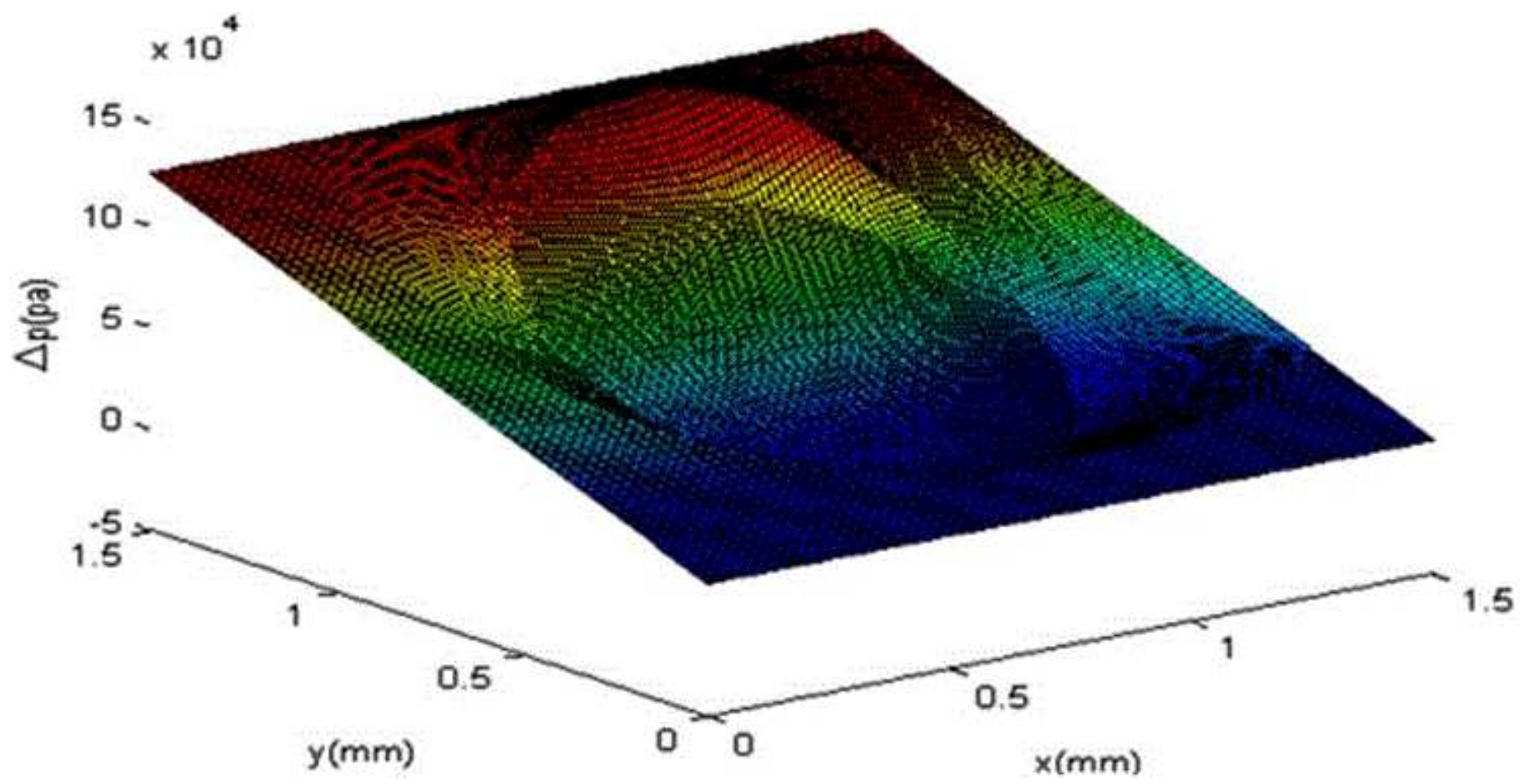

Figure 10

Pressure drop of the first element near the front cavity at maximum backhaul velocity 


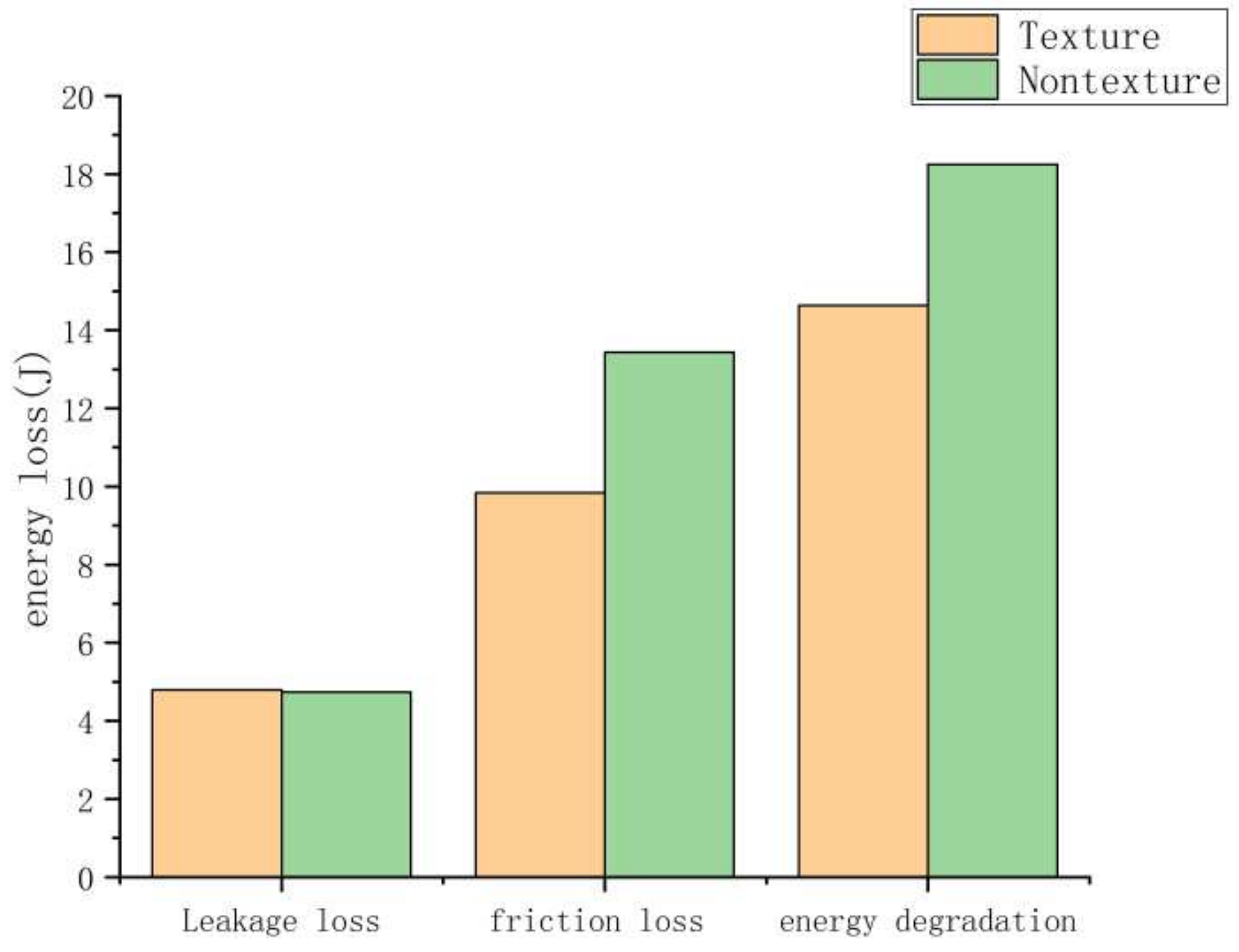

Figure 11

Comparison of energy consumption between the non-textured impact piston pair and cylindrical textured impact piston pair 


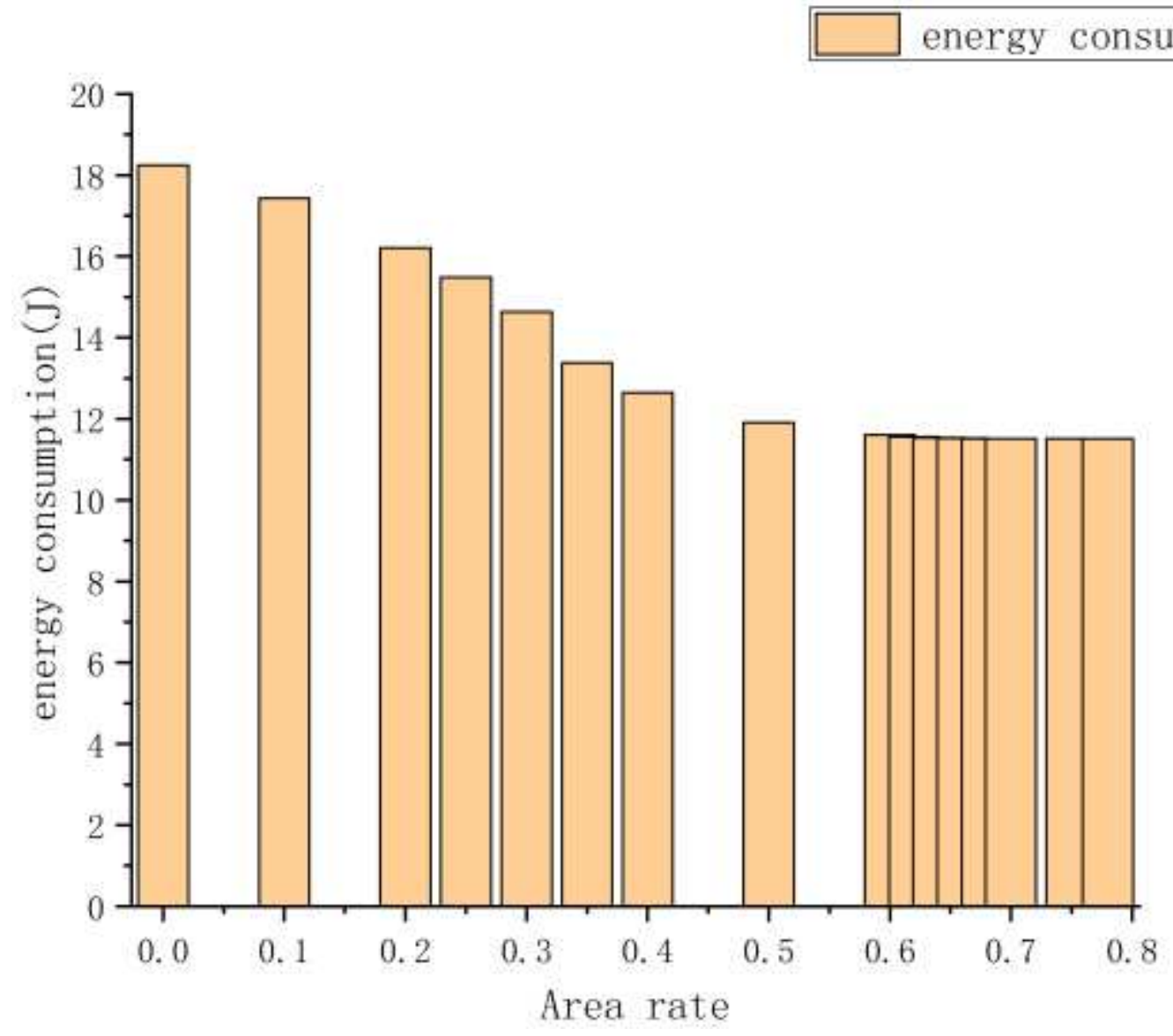

Figure 12

Energy consumption of the impact piston pair with different area ratios textured

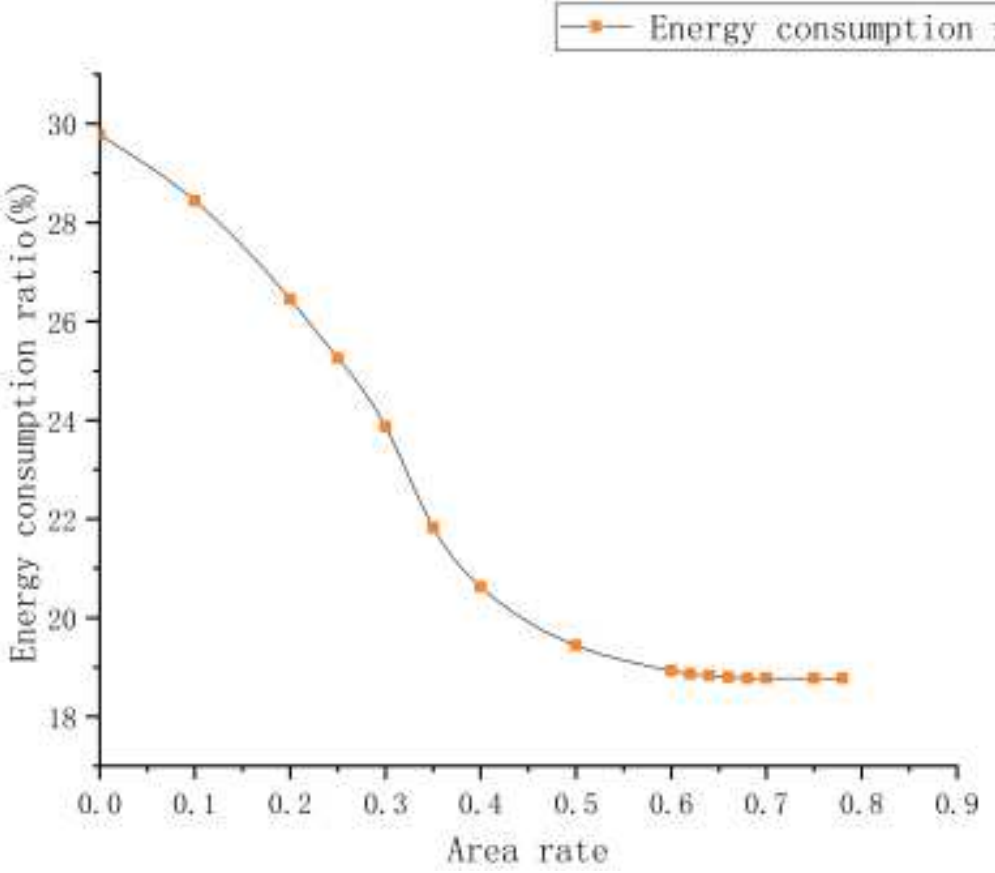

Figure 13

Energy consumption ratio of the impact piston pair with different area ratios textured 


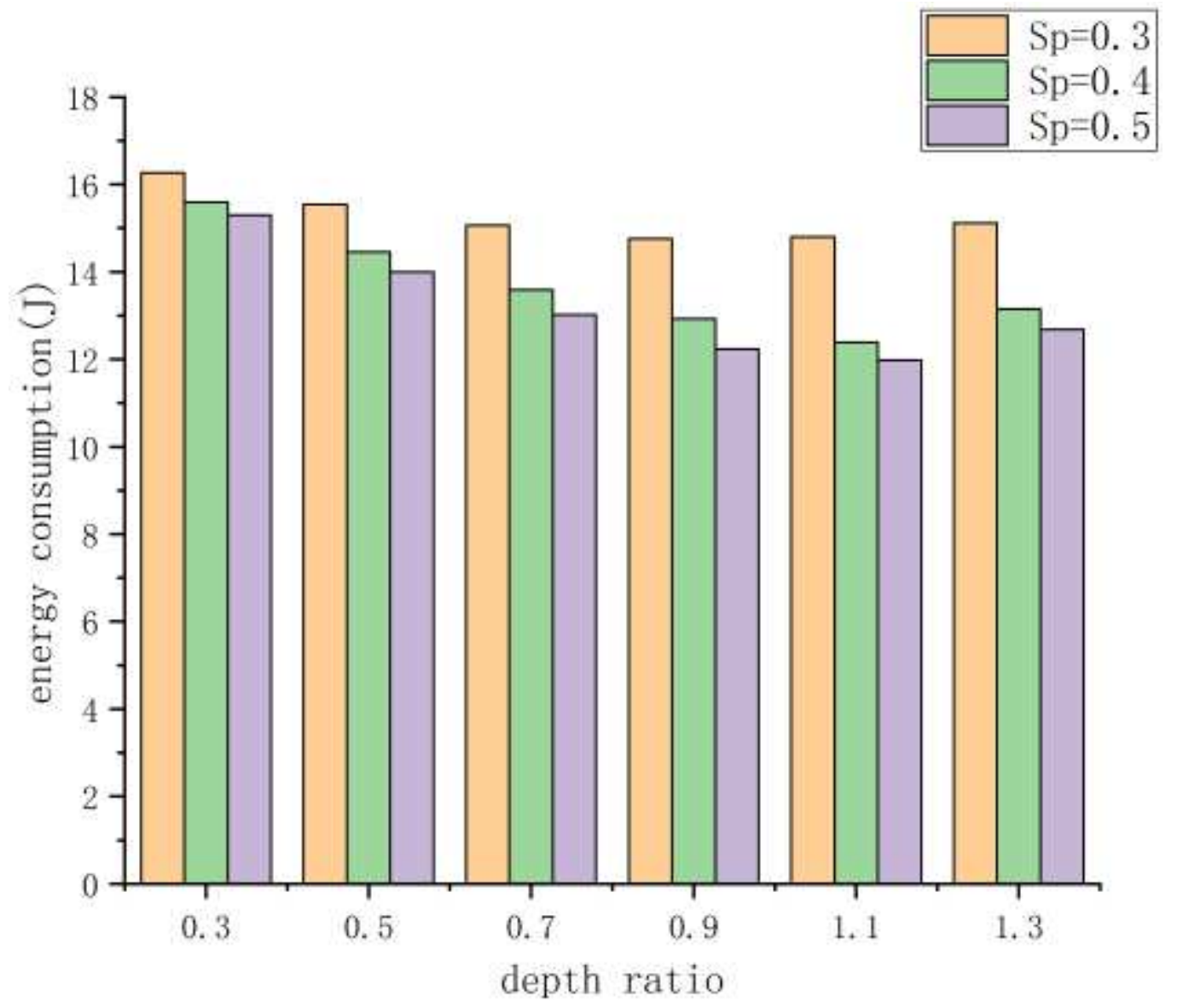

Figure 14

Energy consumption of the impact piston pair with different depth ratios textured under varying area ratios textured 


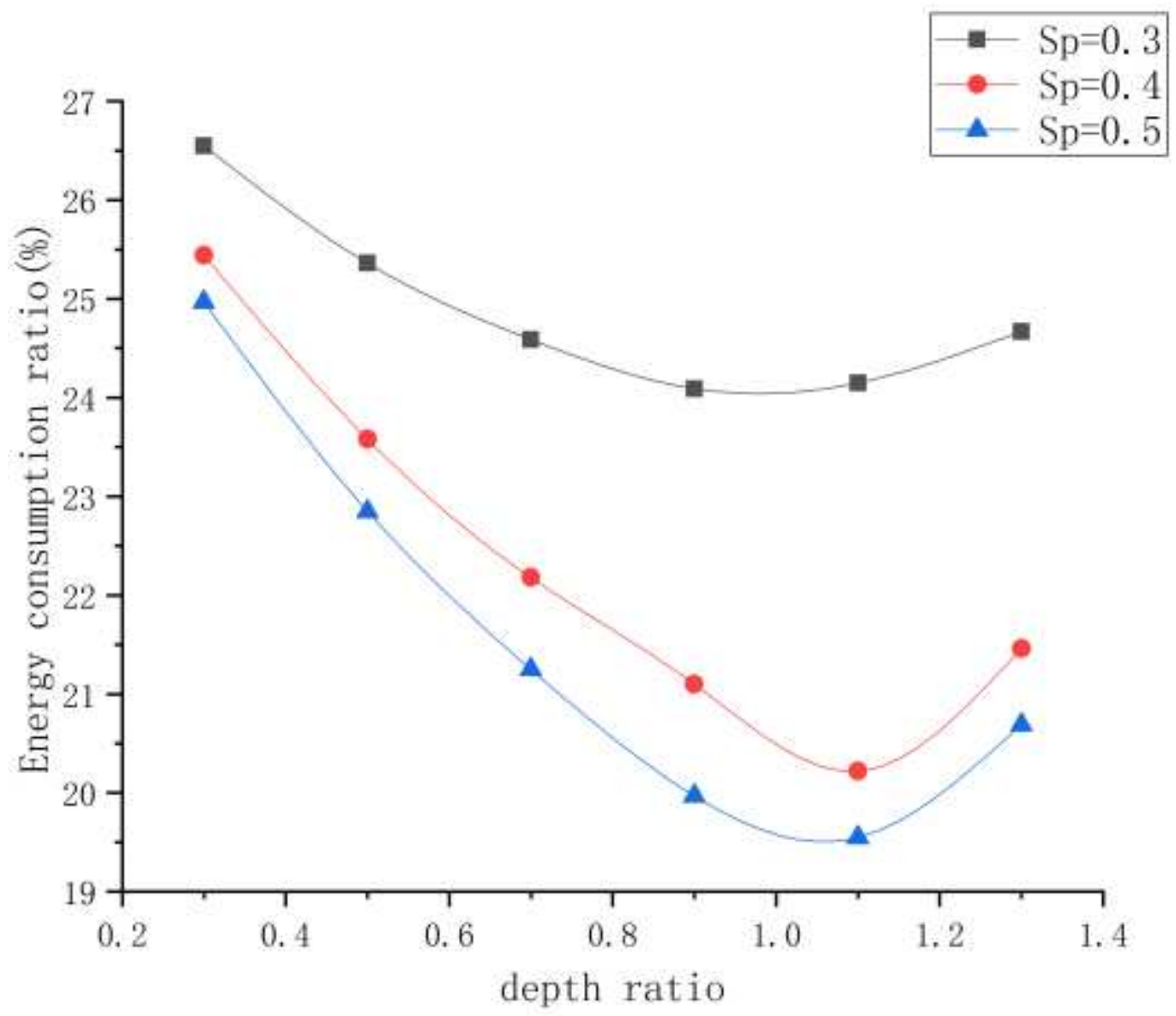

Figure 15

Energy consumption ratio of the impact piston pair with different depth ratios textured under varying area ratios textured 